\title{
Novel 1,1-diphenylhydrazine derivatives of benzofurazan and their dimerization
}

\section{Elena N. Hristea, ${ }^{a}$ Marioara Bem, ${ }^{a}$ Teodor Silviu Balaban, ${ }^{b}$ Andreas Eichhöfer, Miron T. Caproiu, ${ }^{d}$ Constantin Draghici, ${ }^{d}$ Gabriela Ionita, ${ }^{\text {a }}$ Tanta Spataru, ${ }^{\mathrm{a}}$ Cristian Enache, ${ }^{\mathrm{e}}$ Maria Maganu, ${ }^{\mathrm{d}}$ Adrian Beteringhe, ${ }^{\text {,ff }}$ Mihaela Hillebrand,g Titus Constantinescu, and Alexandru T. Balaban*h}

a Institute of Physical Chemistry "Ilie Murgulescu” of the Roumanian Academy, Splaiul Independentei 202, 060021 Bucharest, Roumania

${ }^{b}$ Aix-Marseille Univ., Institut de Sciences Moléculaires de Marseille, UMR 6263, Chirosciences, Marseille, France

${ }^{c}$ Karlsruhe Institute of Technology, Institute of Nanotechnology, Postfach 3640, D-76021, Karlsruhe, Germany

'Institute of Organic Chemistry “C. D. Nenitzescu” of the Roumanian Academy, Splaiul Independentei 202B, Bucharest 15-256, Roumania

${ }^{e}$ Central Laboratory for Phytosanitary Quarantine, Bulevardul Voluntari 11, 077190 Voluntari, Roumania

${ }^{f}$ Lumina - University of South-East Europe, Colentina Road 64B, Bucharest - 021187, Roumania

${ }^{g}$ University of Bucharest, Department of Physical Chemistry, Bulevardul Elisabeta 4-12, Bucharest, Roumania

${ }^{h}$ Texas A\&M University at Galveston, Department of Marine Sciences, Galveston, TX 77553 1675, USA

E-mail: balabana@tamug.edu

\begin{abstract}
In a quest for novel persistent free radicals, two products were obtained from the reaction between 1,1-diphenylhydrazine and 4-chloro-7-nitrobenzofurazan: the expected 1-(4nitrobenzofurazan-7-yl)-2,2-diphenyl-hydrazine 3 formed via an $S_{N} A r$ process, and the unexpected 4,7-benzofurazandione-(bis-1,1-diphenylhydrazone) $\mathbf{4}$ formed from $\mathbf{3}$ by a further ipso substitution and dehydrogenation. Oxidation of $\mathbf{3}$ with solid $\mathrm{PbO}_{2}$ or solid $\mathrm{KMnO}_{4}$ at room temperature affords during the first few minutes a persistent mono-nitro-hydrazyl free radical 6 , which reacts with $\mathrm{NO}_{2}$ and forms another persistent hydrazyl free radical $\mathbf{7}$ having two nitro groups. Two blue dimeric compounds, 11 and 13, were obtained by dimerisation of 6 and 7 respectively, and loss of $\mathrm{N}_{2} \mathrm{O}_{4}$, and their structures were determined by mass spectrometry and NMR spectra. Additionally, single crystal X-ray diffraction was used to ascertain the structures of compounds 4 and 13. Other novel derivatives were prepared either by $N$-alkylation of $\mathbf{3}$ with
\end{abstract}


methyl iodide, which afforded compound $\mathbf{5}$, or by homolytic nitration of $\mathbf{3}$ with gaseous $\mathrm{NO}_{2}$ which yielded the 4,7-dinitrobenzofurazan derivative 8. When gaseous ${ }^{15} \mathrm{NO}_{2}$ was used in a similar reaction, only one ${ }^{15} \mathrm{~N}$-nitro group was present in the product 7 . Persistent free radicals were obtained from 4, 11, or $\mathbf{1 3}$ with $\mathrm{KMnO}_{4}$. Cyclic voltammograms for $\mathbf{3}$ and $\mathbf{8}$ as well as electronic absorption spectra for all new compounds $3,4,5,8,11$, and 13 are discussed.

Keywords: Capto-dative, push-pull, persistent radicals, quinonediimines, cyclic voltammetry, EPR, UV-Vis, RP-TLC, X-ray diffractometry

\section{Introduction}

The extreme stability of the free radical 2,2-diphenyl-1-picrylhydrazyl (DPPH) $)^{1,2}$ is due to a combination of steric and electronic factors. Steric shielding by two ortho-nitro groups prevents its dimerization while the presence of an electron-donor diarylamino group and of a picryl electron-acceptor group provide a unique electronic combination. This "push-pull electronic effect" ${ }^{3}$ has also been called "capto-dative effect", ${ }^{4}$ or "merostabilization". ${ }^{5}$ A quantum-chemical rationalization of such stabilizing effects for free radicals was first provided by Michael Dewar. ${ }^{6}$ Linnett's double quartet theory ${ }^{7}$ allows a graphical representation of DPPH in terms of spins $\alpha$ and $\beta$ : the first two resonance structures for the upper row of Chart 1 (with approximately equal contributions as indicated by the quasi-equality of the hyperfine coupling constants of the two nitrogens in the EPR spectrum) correspond to the Linnett structure shown in the lower row, a covalent bond or an unshared electron pair consists of two electrons with opposite spins $\alpha$ and $\beta$; the remaining three electrons with spins $\alpha, \alpha$ and $\beta$ are distributed between the two nitrogen atoms and their $\mathrm{N}-\mathrm{N}$ bond. Whereas in the Linnett structure each nitrogen atom is shown to have 8 electrons in the valence shell, the $\mathrm{N}-\mathrm{N}$ bond has a higher bond order (1.5). With 3,5-di-tertbutyl substituents on the phenyl rings and with a benzoyl group replacing the picryl group, it was possible to obtain a simpler EPR spectrum proving by variable-temperature EPR spectroscopy that indeed the rotation barrier around the $\mathrm{N}-\mathrm{N}$ bond had a higher value in the free radicals than the barrier in corresponding hydrazines. ${ }^{8}$

The present investigation had as initial objective the synthesis of analogs of DPPH having a 4-nitrobenzofurazan electron-withdrawing group, EWG (4-nitro-2,1,3-benzoxadiazole, also abbreviated as NBD) instead of picryl. Such a group would have a lower steric shielding than picryl and a comparable electron-withdrawing effect, and it might impart interesting fluorescence properties. However, interaction of the unpaired spin with an extended chromophoric system could also lead to charge transfer and thus provide a non-radiative decay from the excited state. Like the Boulton-Katritzky rearrangement of nitro-benzofurazan and -benzofuroxan derivatives, ${ }^{9}$ the NBD moiety may also become involved in processes that move the oxadiazole around the benzo ring. ${ }^{10}$ 


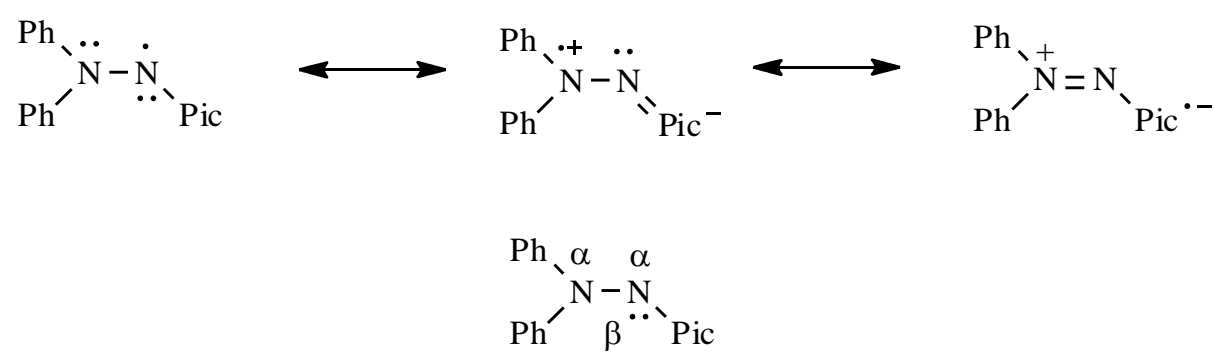

Chart 1. Resonance formulas (upper row) and Linnett structure (lower row) for DPPH (Pic = picryl).

Therefore we performed the reaction between 1,1-diphenylhydrazine 1 and 4-chloro-7nitrobenzofurazan (2, NBD-Cl), obtaining the target push-pull hydrazine 3, along with an unexpected side-product, 4 (Scheme 1). We then investigated in detail chemical and physical properties of the novel compounds which, in spite of having one or two NBD moieties, proved to be non-fluorescent.

\section{Reaction of 4-chloro-7-nitrobenzofurazan with 1,1-diphenylhydrazine and structures of the products}

1,1-Diphenylhydrazine 1 was stirred in ethanol at room temperature with an excess of sodium hydrogen carbonate to which an equimolar amount of NBD-Cl was added. After heating at reflux for one hour and work-up of the reaction mixture, two products were obtained by preparative thin layer chromatography (TLC): 1-(4-nitrobenzofurazan-7-yl)-2,2-diphenylhydrazine $\mathbf{3}$ in 30\% yield, and 4,7-benzofurazandione-(bis-1,1-diphenylhydrazone) 4 in $21 \%$ yield. The reaction mechanism for the expected product 3 involves an $S_{N} A r$ process, ${ }^{11}$ while for the rather unexpected product $\mathbf{4}$ an ipso-substitution of the nitro group by the nucleophilic $\mathbf{1}$ must be invoked followed by an oxidation to form the quinonediimine system (Scheme 1). Indeed, on treating separately 1,1-diphenylhydrazine $\mathbf{1}$ with the push-pull NBD-diphenylhydrazine $\mathbf{3}$ in warm ethanol in the presence of $\mathrm{NaHCO}_{3}$, we obtained again compound 4 but only in $18 \%$ isolated yield.

By reacting compound $\mathbf{3}$ with methyl iodide under conditions of phase transfer catalysis, ${ }^{12}$ the $N$-methyl-derivative 5 was obtained in 52\% yield after TLC, confirming the structure of $\mathbf{3}$. In contrast to the highly reactive $\mathbf{3}$ or $\mathbf{4}$, the air-stable $N$-methyl derivative $\mathbf{5}$ did not show multiple spots upon TLC purification.

Single crystals of 4 could be grown by slow diffusion of $n$-heptane into dry dichloromethane, and interestingly two polymorphs were encountered: (i) rather large orangeochre prisms which could be easily cleaved and (ii) very thin but rather long red needles. The red needles were mounted at the ANKA Synchrotron in Karlsruhe, and although they diffracted Xrays well, giving a reasonable data set, their structure could not be solved by direct methods. In contrast, the large prisms could be solved by conventional techniques showing without doubt that 4 was present in this mixture of polymorphs. 


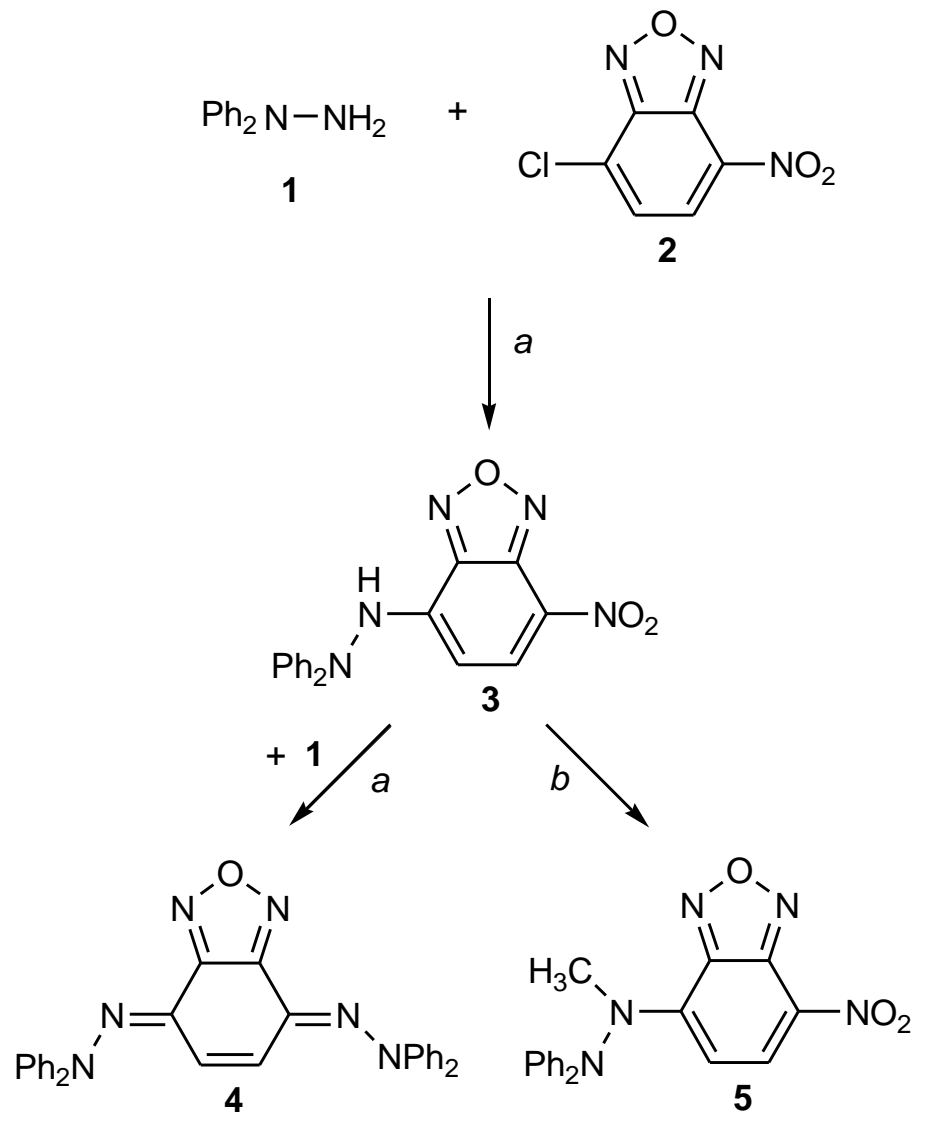

Scheme 1. Formation of compounds 3 and 4 from the reaction of 1,1-diphenylhydrazine (1) and NBD-Cl (2). Reagents and conditions: a) $\mathrm{NaHCO}_{3}$, EtOH, $\Delta, 1$ h; b) $\mathrm{CH}_{3} \mathrm{I}, \mathrm{NaOH}, 15$-crown-5, $\mathrm{CH}_{2} \mathrm{Cl}_{2}, \mathrm{RT}, 5 \mathrm{~h}$.
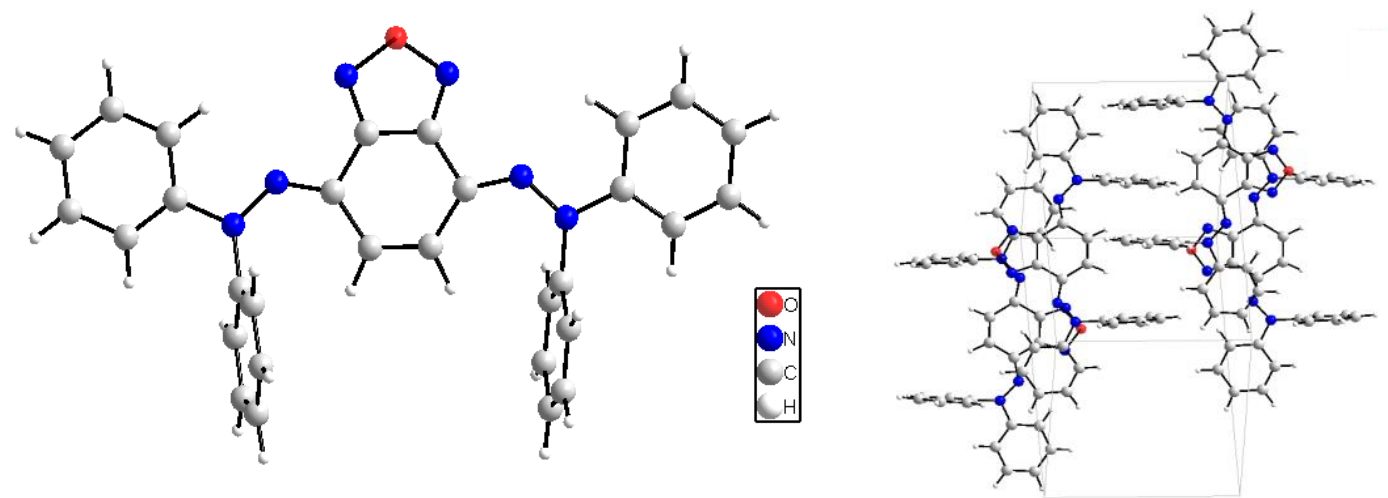

Figure 1. Structure of an orange single crystal of $\mathbf{4}$ as determined by X-ray analysis. At right, the crystal packing showing four molecules within the unit cell. 
In the crystal, the furazan O-N bonds are $1.389 \AA$ long with an NON angle of $111.6^{\circ}$. The exocyclic quinonoid $\mathrm{C}=\mathrm{N}$ double bonds are $1.301 \AA$ long and tilted slightly towards the fivemembered ring alligning almost collinearly the bonds of the two para- nitrogen atoms on either side of the $C_{2 \mathrm{v}}$ symmetric molecule. Interestingly, concerning these quinonoid double bonds, only the $(E, E)$ isomer shown in Figure 1 has been found, which can be explained by a probable electrostatic repulsion between the furazan nitrogen atom and the $\mathrm{sp}^{3}$-hybridized hydrazonic nitrogen atom in hypothetical $Z$-stereoisomers (but possibly the red needles may contain another stereoisomer). The two $N$-phenyl bonds are slightly different in length, one being $1.417 \AA$ while the other one is $1.440 \AA$ long, a fact reflecting that the former phenyl ring is engaged in strong $\pi-\pi$ interactions (Figure 1 and S1 - Supplementary Material). The furazan 5-membered ring overlaps completely with such a phenyl ring ensuring a 2-D connected network with $3.367 \AA$ as the shortest intermolecular distance. Additionally, as shown in the right part of Figure 1, the other $N$-phenyl groups stack in a perpendicular direction forming a staircase-like architecture with $3.45 \AA$ shortest distances between the ladders.

\section{Formation of free radicals from compound 3}

The electron-withdrawing 4-nitrobenzofurazan substituent and the diphenylamino group make compound 3 a typical precursor for persistent push-pull aminyl radicals related to DPPH. On treating compound 3 in deaerated methylene chloride with solid $\mathrm{PbO}_{2}$ or solid $\mathrm{KMnO}_{4}$ at room temperature, two free radicals were evidenced by EPR spectroscopy, as shown in Figure 2.
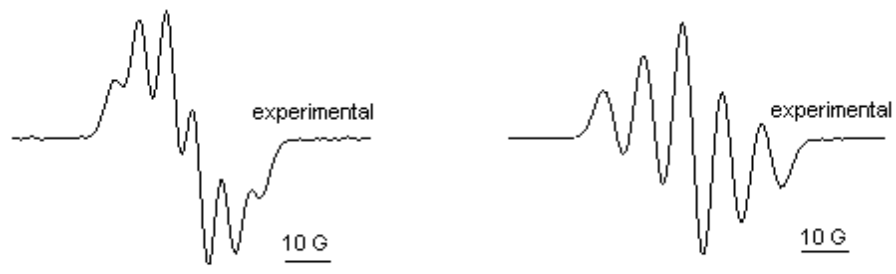

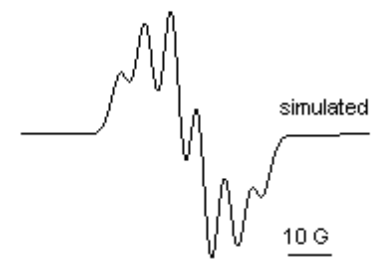

a

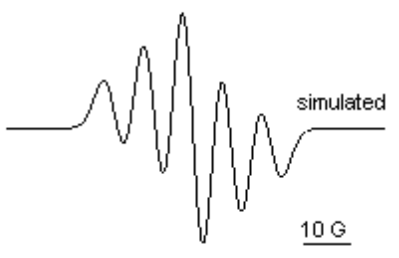

b

Figure 2. Experimental (upper traces) and simulated (lower traces) of EPR spectra of oxidation products of 3 in $\mathrm{CH}_{2} \mathrm{Cl}_{2}$ with solid $\mathrm{KMnO}_{4}$ after 3 minutes (a) and after 7 minutes (b).

By preparative TLC analysis of the reaction mixture after $7-10$ minutes, the new spots, along with unreacted $\mathbf{3}$, allowed the detection and identification of compounds $\mathbf{1 1}$ and $\mathbf{1 3}$, formed 
from the corresponding persistent free radicals $\mathbf{6}$ and 7, respectively, according to the reaction mechanism depicted in Scheme 2.<smiles>NNc1ccc([N+](=O)[O-])c2nonc12</smiles><smiles>C1=CC[CH+]1</smiles><smiles>O=[N+]([O-])c1c(Cl)c(Cl)c2nonc2c1[N+](=O)[O-]</smiles><smiles></smiles><smiles>NN(N)c1ccc([N+](=O)[O-])c2nonc12</smiles><smiles>C[14C](C)=O</smiles><smiles></smiles><smiles>NN=C1C=CC([N+](=O)[O-])([N+](=O)[O-])c2nonc21</smiles><smiles>N/N=C1/C=C/C(=C2/C=C/C(=N\N)c3nonc32)c2nonc21</smiles><smiles>N/N=C1/C([N+](=O)[O-])=C/C(=C2/C=C([N+](=O)[O-])/C(=N/N)c3nonc32)c2nonc21</smiles>

Scheme 2. Formation of compounds 8, 11, and 13 via the persistent free radicals 6 and 7 as well as the not isolated intermediates $\mathbf{1 0}$ and 12. $* \mathrm{~N}$ in $* \mathrm{NO}_{2}$ stands for either ${ }^{14} \mathrm{~N}$ or ${ }^{15} \mathrm{~N}$. Reagents and conditions: $a$ ) $\mathrm{HNO}_{3}$ /oleum, $\left.100-105{ }^{\circ} \mathrm{C} ; b\right) \mathrm{NaHCO}_{3}$, EtOH, $\Delta, 1 \mathrm{~h}$.

The oxidation of $\mathbf{3}$ leads to the initial formation of radical $\mathbf{6}$ displaying an EPR spectrum with 6 lines, which does not have the steric shielding of DPPH, and therefore dimerizes easily to 10 which then disproportionates affording $2 \mathrm{NO}_{2} \rightleftharpoons \mathrm{N}_{2} \mathrm{O}_{4}$ and the deep-blue diphenoquinonediiminic compound 11 exhibiting in the mass spectrum a molecular peak at $\mathrm{m} / \mathrm{z}=$ 600 Daltons. Concurrently, 6 also reacts with the in situ formed $\mathrm{NO}_{2}$ as shown in Scheme 2 affording at slightly longer reaction times the free radical 7 having an EPR spectrum with 5 lines. In analogous reactions to preceding ones, dimerization and disproportionation of 7 leads to a different blue compound, 13 with the molecular peak at $m / z=690$ Daltons. Reversible hydrogen 
abstraction from $\mathbf{3}$ transforms radical $\mathbf{7}$ into the neutral dinitro-substituted compound $\mathbf{8}$. One should stress that structural assignments for $\mathbf{6}$ and $\mathbf{7}$ are based only on plausible interpretations of ESR spectra.

In a separate experiment we could confirm the homolytic nitration of $\mathbf{3}$ with gaseous $\mathrm{NO}_{2}{ }^{13}$ Nitrogen dioxide, which is more reactive than nitric oxide, was generated from solid powdered sodium nitrite and a solid support, ${ }^{14}$ namely silica gel for chromatography, in a biphasic solid liquid system mediated by the crown ether 15-crown-5 in methylene chloride. We also used separately ${ }^{15} \mathrm{~N}$-labeled sodium nitrite, and the asterisk in Scheme 2 can signify either one of the two stable nitrogen isotopes. It was thus found that the dinitro-derivative $\mathbf{8}$ is formed by homolytic substitution in $35-40 \%$ yield. Thus, 1-(4,6-dinitrobenzofurazan-7-yl)-2,2diphenylhydrazine was formed when using normal $\mathrm{NaNO}_{2}$, and 1-(4-[ $\left.{ }^{14} \mathrm{~N}\right]$ nitro-6- $\left[{ }^{15} \mathrm{~N}\right]$ nitrobenzofurazan-7-yl)-2,2-diphenylhydrazine was obtained when using $\left[{ }^{15} \mathrm{~N}\right] \mathrm{NaNO}_{2}$. No scrambling of the label occurred.

An alternative synthesis of $\mathbf{8}$ could be achieved by first nitrating NBD-Cl (2) with nitric acid and oleum ${ }^{15}$ followed by conversion of the resulting dinitro-derivative $\mathbf{9}$ into $\mathbf{8}$ by an $S_{N} A r$ process on using diphenylhydrazine (1) as the nucleophile. In this case no ipso-substitution of either nitro group could be observed.

For both free radicals 6 and 7, the $g$-factor agrees with the value associated with hydrazyls. ${ }^{2}$ Hyperfine coupling constants used for the simulated EPR spectra are presented in Table 1.

Table 1. EPR data for hydrazyls 6 and 7 (Scheme 2; Figure 2a for 6 and Figure 2b for 7)

\begin{tabular}{cccc}
\hline Free radical & $g$ & \multicolumn{2}{c}{$\begin{array}{c}\text { Hyperfine coupling constants } \\
\text { (Gauss) }\end{array}$} \\
\hline $\mathbf{6}$ & 2.0037 & $\mathrm{a}_{\mathrm{N} 1}=6.04$, & $\mathrm{a}_{\mathrm{N} 2}=5.54, \quad \mathrm{a}_{\mathrm{N} 3}=3.14, \quad \mathrm{a}_{\mathrm{N} 4}=1.00$ \\
$\mathbf{7}$ & 2.0037 & $\mathrm{a}_{\mathrm{N} 1}=8.04, \quad \mathrm{a}_{\mathrm{N} 2}=8.03$ & \\
\hline
\end{tabular}

A further experiment confirming the structural assignments was the oxidation of $\mathbf{3}$ at room temperature in $\mathrm{CH}_{2} \mathrm{Cl}_{2}$ with solid $\mathrm{KMnO}_{4}$ in the presence of ascorbic acid (molar ratio 10:1 for 3:ascorbic acid). The EPR signal of $\mathbf{6}$ as in Figure 2a was constant for about 15 minutes after which it decreased, but no formation of $\mathbf{7}$ as in Figure $2 \mathrm{~b}$ was observed. On the other hand, oxidation of compound 8 with solid $\mathrm{KMnO}_{4}$ at room temperature in $\mathrm{CH}_{2} \mathrm{Cl}_{2}$ afforded radical 7 with five lines as in Figure $2 \mathrm{~b}$ (intensity ratio $1: 2: 3: 2: 1$ ), $g=2.0037, \mathrm{a}_{\mathrm{N} 1}=8.15$ and $\mathrm{a}_{\mathrm{N} 2}=8.05$. The slightly different an values from those presented in Table 1 are probably due to the fact that the latter values are affected by small amounts of $\mathbf{6}$ present in solution.

In the case of DPPH, no dimerization is detected in solution (although in single crystals some evidence for dimer formation was reported). ${ }^{16}$ Definite proof for the dimeric structure of compound 13 came again from single crystal X-ray diffraction. Using similar conditions as for the growth of crystals of $\mathbf{4}$, we obtained thin blue needles that required synchrotron radiation for their X-ray analysis. The structure was solved by direct methods showing that among the six possible syn-anti stereoisomers, the predominant form is the one presented in Figure 3. 

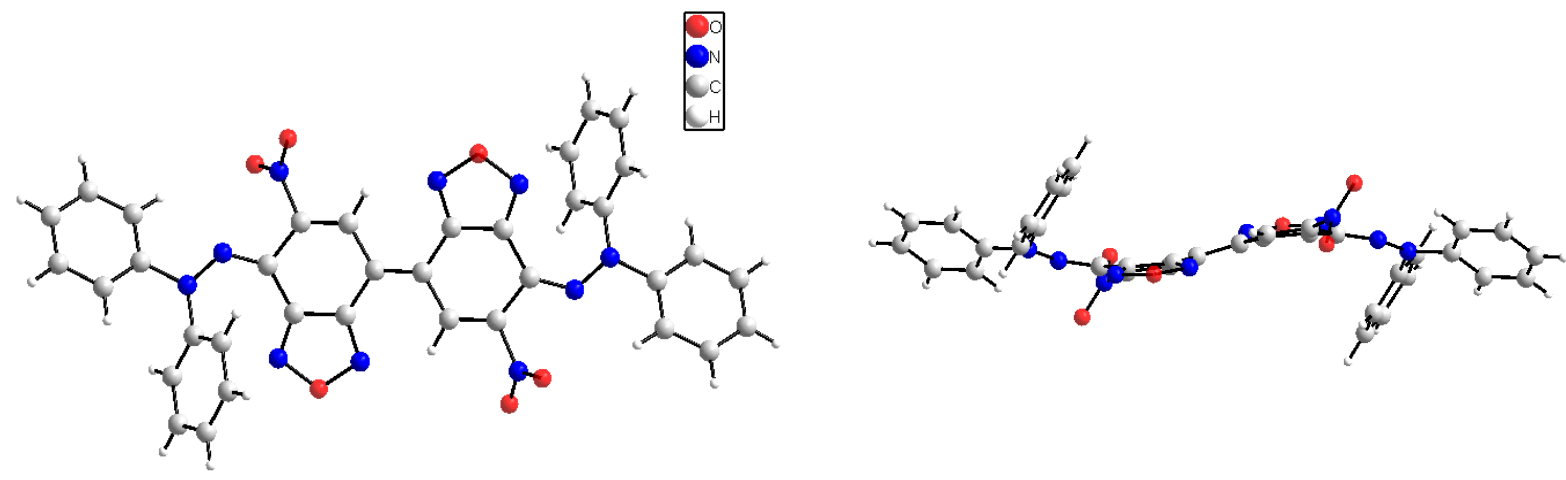

Figure 3. Structure of $\mathbf{1 3}(\mathrm{m} / \mathrm{z}=690)$ by single crystal X-ray analysis. At right, a view of the nonplanar conjugated system.

In structure 13 the two benzofurazan moieties are oriented in opposite directions with a common central $\mathrm{C}=\mathrm{C}$ double bond which is $1.385 \AA$ long. This particular double bond is thus trans and enables a weak $\mathrm{C}-\mathrm{H} \bullet \bullet \mathrm{N}$ hydrogen bond between the phenyl protons and the furazan nitrogen atoms. A cis double bond would have positioned two furazanic nitrogens in close proximity generating a less stable structure. The two central benzo rings in $\mathbf{1 3}$ are coplanar to within less than $2^{\circ}$. In the case of a central single bond the biphenyl system would not have been coplanar exhibiting a rotation barrier giving rise to enantiomers. Interestingly, chirality is however present in the crystal due to the S-shaped form adopted by the conjugated system, as shown in the right part of Figure 3. Extended chromophoric systems involving diphenoquinonediimides were thoroughly investigated more than 50 years ago by Roger Adams and coworkers. ${ }^{17}$ In our particular case, the combination of the furazan ring and the nitro group on the benzo ring, contrary to 4, ensures that in 13 both diphenylamino moieties of the exocyclic diphenoquinonediimide are now facing the furazan ring. Formally they are still $E$ as the nitro group has a higher priority than the furazan nitrogen atom. Thus the correct designation of the obtained stereoisomer $\mathbf{1 3}$ is E-trans-E. The nitro groups have a $52.9^{\circ}$ torsion angle to the phenyl rings and all point in the same direction within stacks of off-setted molecules having a $5.48 \AA$ distance between neighboring nitrogen atoms of the nitro group. The $\mathrm{C}-\mathrm{N}$ distance is $1.478 \AA$, typical for non-conjugated nitroarenes. The $\mathrm{C}=\mathrm{N}$ bonds are rather short (1.309 $\AA$ ) while the $\mathrm{N}-\mathrm{N}$ bond is $1.330 \AA$. Packing diagrams of compound $\mathbf{1 3}$ in the crystal are presented in Figure S2 Supplementary Material.

\section{Formation of persistent radicals from compounds $(4,11$ and 13$)$}

Interestingly, compounds 4, 11 and 13 present as solids weak but reproducible broad EPR signals. Furthermore, when submitted to TLC, although initially pure, several new spots appear upon elution of the silica gel plates. No rigorous exclusion of oxygen was made, neither from the solvents nor from the elution chamber, so that these bis-hydrazones might actually be readily 
oxidized to corresponding mono-hydrazyl- $N$-oxides. Due to the absence of a capto-dative stabilization and absence of severe steric hindrance, their persistence is much lower than that of 6, 7 or DPPH.

Compound 4 in the solid state presents an EPR spectrum with $g=2.0031$. On dissolution in $\mathrm{CH}_{2} \mathrm{Cl}_{2}$ this signal disappears and reappears on evaporating the solvent (Figure 4a). By oxidizing compound 4 with solid $\mathrm{KMnO}_{4}$ in $\mathrm{CH}_{2} \mathrm{Cl}_{2}$ a persistent free radical (presumably the radical-cation from 4) with five lines is obtained (Figure $4 \mathrm{~b}$ ) with the following hyperfine coupling constants: $\mathrm{a}_{\mathrm{N} 1}=8.50 \mathrm{G}, \mathrm{a}_{\mathrm{N} 2}=8.48 \mathrm{G}$ and with $g=2.0034$. The intensity of the EPR spectrum decreases appreciably in 10 minutes.

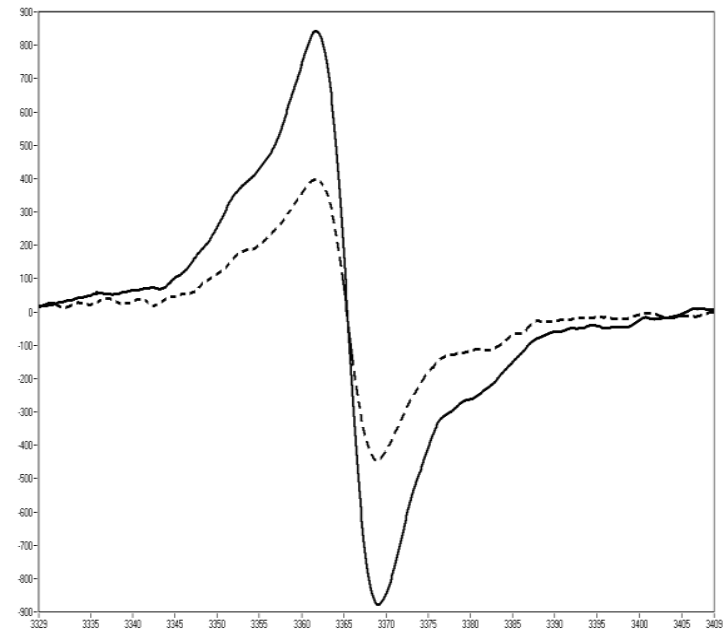

a

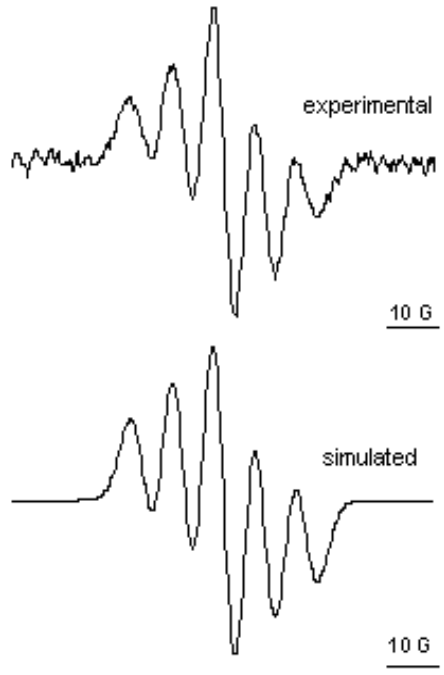

b

Figure 4. EPR Spectrum of compound 4; a, in solid state (full line); after dissolution in methylene chloride and evaporaration of the solvent (dashed line); $b$, after dissolution in methylene chloride and oxidation with $\mathrm{KMnO}_{4}$ solid (experimental and simulated).

A similar behaviour is encountered for the dimeric compounds 11 and $\mathbf{1 3}$ which both exhibit in the solid state a weak EPR signal. Upon dissolution in methylene chloride this signal disappears but it is reformed upon evaporation of the solvent. By oxidizing compounds 11 and 13 with solid $\mathrm{KMnO}_{4}$ in $\mathrm{CH}_{2} \mathrm{Cl}_{2}$, persistent free radicals (presumably radical-cations) with fiveline ESR spectra are obtained (Figures 5a, 5b, and Table 2); their intensity decreases in time, faster for the less sterically-shielded structure devoid of nitro groups. 


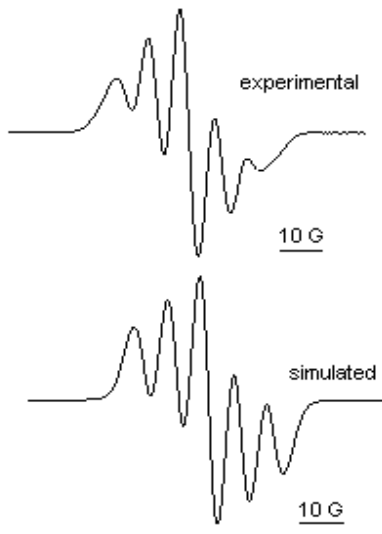

a
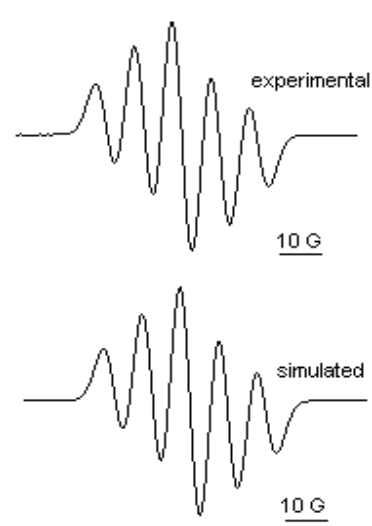

b

Figure 5. EPR Spectra in deaerated methylene chloride after oxidation with solid $\mathrm{KMnO}_{4}$ : a, for 11 (experimental and simulated) and b, for $\mathbf{1 3}$ (experimental and simulated)

Table 2. EPR Spectra of the radicals obtained by oxidizing dimeric compounds $\mathbf{1 1}$ and $\mathbf{1 3}$ with solid $\mathrm{KMnO}_{4}$ in $\mathrm{CH}_{2} \mathrm{Cl}_{2}$ (Figure 5)

\begin{tabular}{clc}
\hline $\begin{array}{c}\text { Dimeric } \\
\text { compound }\end{array}$ & $g$ & $\begin{array}{c}\text { Hyperfine coupling constants } \\
\text { (Gauss) }\end{array}$ \\
\hline $\mathbf{1 1}$ & 2.0033 & $\mathrm{a}_{\mathrm{N} 1}=7.10, \mathrm{a}_{\mathrm{N} 2}=7.07$ \\
$\mathbf{1 3}$ & 2.0033 & $\mathrm{a}_{\mathrm{N} 1}=9.21, \mathrm{a}_{\mathrm{N} 2}=8.28$ \\
\hline
\end{tabular}

\section{Cyclic voltammetry}

Comparative studies were undertaken using cyclic voltammetry for three related compounds (2,2-diphenyl-1-EWG-hydrazines) with electron-withdrawing groups (EWGs): 3, 8, and DPPH$\mathrm{H}$ with 1, 2, and 3 nitro groups, respectively. The results are presented in Figures 6 and 7, and Table 3. While compound $\mathbf{3}$ is oxidized at the same potential as DPPH-H but it is reduced only partly, compound $\mathbf{8}$ is oxidized and reduced at higher potentials than $\mathbf{3}$ and DPPH-H.

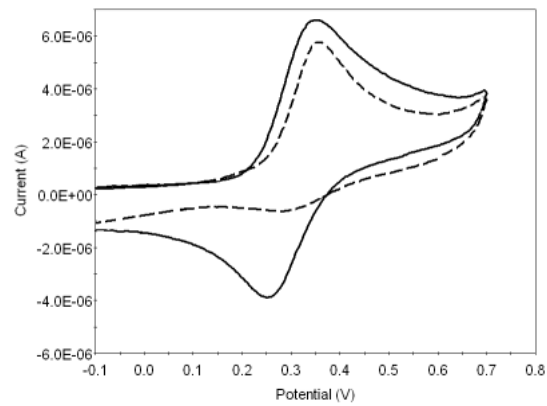

Figure 6. Cyclic voltammograms recorded for a concentration of $10^{-3} \mathrm{M}$ of DPPH-H (full line) and 3 (dashed line) in acetonitrile (vs. $\mathrm{Ag} / \mathrm{AgCl}$ ) at a scan rate of $0.5 \mathrm{~V} \mathrm{~s}^{-1}$; supporting electrolyte $10^{-1} \mathrm{M}$ TBAP (tetra- $n$-butylammonium perchlorate); scanning potential from $-0.1 \mathrm{~V}$ to $0.7 \mathrm{~V}$. 


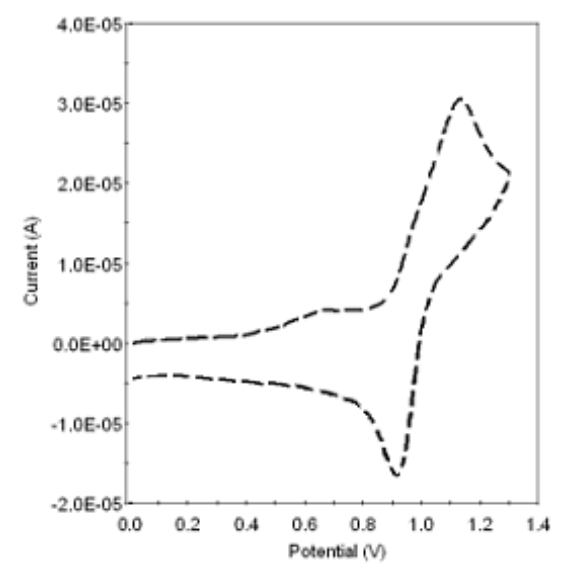

Figure 7. Cyclic voltammogram for 8 at a concentration of $10^{-3} \mathrm{M}$; scan rate of $0.1 \mathrm{~V} \mathrm{~s}^{-1}$, supporting electrolyte $10^{-1} \mathrm{M}$ TBAP; scanning potential from $0 \mathrm{~V}$ to $1.3 \mathrm{~V}$ (vs. $\mathrm{Ag} / \mathrm{AgCl}$ ).

Table 3. Peak potentials $\left(\mathrm{V}\right.$ vs. $\mathrm{Ag} / \mathrm{Ag}^{+}$) for oxidation (EpaI) and reduction (EpcI) of DPPH-H, 3 and $\mathbf{8}$ in acetonitrile in the presence of TBAP $\left(10^{-1} \mathrm{M}\right)$ (Figures 6 and 7).

\begin{tabular}{ccc}
\hline Compound & EpaI & EpcI \\
\hline DPPH-H & 0.353 & 0.250 \\
$\mathbf{3}$ & 0.353 & 0.292 \\
$\mathbf{8}$ & 1.13 & 0.920 \\
\hline
\end{tabular}

The cyclic voltammogram of compound $\mathbf{4}$ is shown in Figure 8 and it has waves corresponding to the oxidized form 4 , the reduced form with two $\mathrm{NH}$ bonds, and also a peak with low potential value that is probably due to a partly reduced free radical with one NH bond (Table 4).

\section{Absorption spectra of compounds $(3,4,5,8,11,13)$ and the anions of (3) and DPPH-H}

Table 5 lists the UV-Vis absorption bands of DPPH-H and $\mathbf{3}$, of their anions, and of compounds 4, 5, 8, 11, and 13. One can observe that compounds 3,8 , and the anion of 3 absorb at appreciably higher wavelengths than DPPH and $\mathrm{DPPH}^{-}$(anion of DPPH-H). This bathochromic effect must be due to the difference between the NBD moiety and the picryl group. It should be mentioned again that none of the new compounds $(\mathbf{3}, \mathbf{4}, \mathbf{5}, \mathbf{8}, \mathbf{1 1}$, or $\mathbf{1 3})$ were fluorescent. 


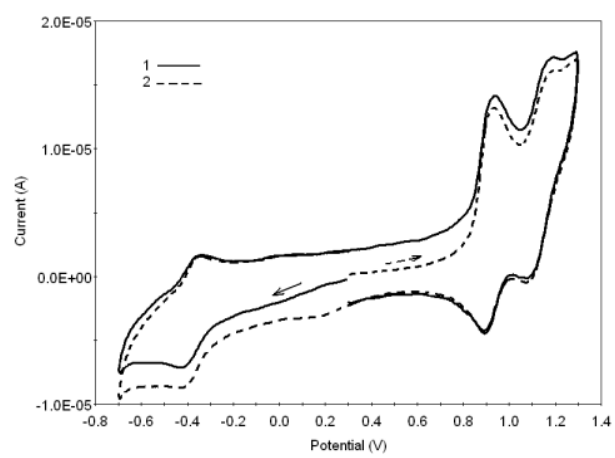

Figure 8. Cyclic voltammogram for a concentration of $10^{-3} \mathrm{M}$ of compound 4 at a scan rate of $0.1 \mathrm{~V} \mathrm{~s}^{-1}$ at $30^{\circ} \mathrm{C}$; supporting electrolyte: $10^{-1} \mathrm{M}$ TBAP. Full line (1), scanning potential from 0.3 $\mathrm{V}$ to $-0.7 \mathrm{~V}$ : first (cathodic) step, from $-0.7 \mathrm{~V}$ to $1.3 \mathrm{~V}$ : second (anodic) step; and from 1.3 to $0.3 \mathrm{~V}$ : third (backward) step. Dashed line (2), scanning potential from $0.3 \mathrm{~V}$ to $1.3 \mathrm{~V}$ : first (anodic) step; from $1.3 \mathrm{~V}$ to $-0.7 \mathrm{~V}$ : second (cathodic) step; and from $-0.7 \mathrm{~V}$ to $0.3 \mathrm{~V}$ : third (backward) step (all potentials vs. $\mathrm{Ag} / \mathrm{AgCl}$ ).

Table 4. Oxidation and reduction peak potentials (V vs. $\mathrm{Ag} / \mathrm{AgCl}$ ) of compound 4 in the presence of TBAP as supporting electrolyte (concentration, $10^{-1} \mathrm{M}$ )

\begin{tabular}{|c|c|c|c|c|c|c|c|c|}
\hline \multicolumn{2}{|c|}{$1^{\text {st }}$ peak } & \multicolumn{2}{|c|}{$2^{\text {nd }}$ peak } & \multicolumn{2}{|c|}{$3^{\text {rd }}$ peak } & \multirow[b]{2}{*}{$\Delta \mathrm{EpI}^{\mathrm{a}}$} & \multirow[b]{2}{*}{$\Delta \mathrm{Ep}^{\mathrm{b}}{ }^{\mathrm{b}}$} & \multirow[b]{2}{*}{$\Delta \mathrm{Ep} I I I^{\mathrm{c}}$} \\
\hline EpaI & EpcI & EpaII & EpcII & EpaIII & EpcIII & & & \\
\hline-0.360 & -0.420 & 0.940 & 0.885 & 1.170 & 1.095 & 0.060 & 0.055 & 0.080 \\
\hline
\end{tabular}

${ }^{\mathrm{a}} \Delta \mathrm{EpI}=\mathrm{EpaI}-\mathrm{EpcI} ;{ }^{\mathrm{b}} \Delta \mathrm{EpII}=\mathrm{EpaII}-\mathrm{EpcII} ;{ }^{\mathrm{c}} \Delta \mathrm{EpIII}=\mathrm{EpaIII}-\mathrm{EpcIII}$

Table 5. Absorption maxima $\left(\lambda_{\max }\right)$ in the visible region in $\mathrm{CH}_{2} \mathrm{Cl}_{2}$ for $\mathrm{DPPH}-\mathrm{H}$, its anion $\left(\mathrm{DPPH}^{-}\right)$, compounds $\mathbf{3}, \mathbf{4}, \mathbf{5}, \mathbf{8}, \mathbf{1 1}, \mathbf{1 3}$ and the anion of $\mathbf{3}$

\begin{tabular}{|c|c|c|}
\hline Compound & $\lambda_{\max }(\mathrm{nm})$ & $\varepsilon\left(\mathrm{L} \times \mathrm{M}^{-1} \times \mathrm{cm}^{-1}\right)$ \\
\hline DPPH-H & 318 & 13100 \\
\hline $\mathrm{DPPH}^{-\mathrm{a}}$ & 424 & - \\
\hline 3 & 451 & 9500 \\
\hline \multirow{2}{*}{ Anion of $3^{\text {a }}$} & 405 & 16800 \\
\hline & 500 & 28210 \\
\hline 4 & 483 & Not determined \\
\hline \multirow{2}{*}{5} & 332 & 6230 \\
\hline & 477 & 13900 \\
\hline \multirow[t]{2}{*}{8} & 389 & 17800 \\
\hline & 492 & 8370 \\
\hline 11 & 636 & Not determined \\
\hline 13 & $\begin{array}{l}486 \\
617\end{array}$ & Not determined \\
\hline
\end{tabular}

${ }^{\mathrm{a} D P P H}-\mathrm{H}$ and $\mathbf{3}$ in the presence of triethylamine. 


\section{Hydrophobic-hydrophilic balance}

The hydrophobicity of organic compounds is of prime importance for their applications, especially in biomedicine. The experimental partition coefficient between 1-octanol and water $(\log P)$ can be calculated fairly accurately by means of various programs, e. g. $A \log P{ }^{18-20}$ Another experimental approach is based on reverse-phase TLC (RP-TLC) and produces the molecular hydrophobicity, $R_{M 0}{ }^{21-23}$ In the following we present this parameter for the newly synthesized compounds $\mathbf{3}, \mathbf{4}$, and $\mathbf{5}$ and for the oxidation products of $\mathbf{3}$, namely $\mathbf{8}, \mathbf{1 1}$, and $\mathbf{1 3}$. For comparison we also include DPPH-H, and the starting materials $\mathbf{1}$ (1,1-diphenylhydrazine), 2 (NBD-Cl), 9 (dinitro-benzofurazan-Cl), and picryl chloride (14). Experiments with RP-TLC involved the stationary phase $\mathrm{C}_{18}$ covalently bonded to silica gel, and various concentrations of aqueous ethanol as the mobile phase. The molecular hydrophobicity, $R_{M 0}$ was calculated by means of equations (1) and (2), where the alcohol concentration $K$ was extrapolated to zero, and $b$ is the slope of the plot for the $R_{M}$ value when the alcohol concentration is varied from $\mathrm{A}=95 \%$ to $\mathrm{D}=80 \%$, as seen in Table 6 . The same Table presents the statistical parameters $R^{2}$ (the correlation coefficient $R$ is always a negative number close to -1 ), Fisher parameter $F$, and the standard deviation $S D$.

$$
\begin{aligned}
& R_{M}=\log \left(1 / R_{f}-1\right) \\
& R_{M}=R_{M 0}+b K
\end{aligned}
$$

Table 6. Comparative results for $R_{M}, R_{M 0}, b$ and calculated $A \log P$ of compounds $\mathbf{1 , 2}, \mathbf{3}, \mathbf{4}, \mathbf{5}, \mathbf{8}$,

\begin{tabular}{|c|c|c|c|c|c|c|c|c|c|c|}
\hline \multirow[t]{2}{*}{ Comp. } & \multicolumn{4}{|c|}{$R_{M}$} & \multicolumn{2}{|c|}{$\begin{array}{l}\text { Hydrophobicity } \\
\text { characteristics }\end{array}$} & \multicolumn{3}{|c|}{ Statistical parameters } & \multirow{2}{*}{$\begin{array}{l}A \log P \\
\text { calc. }\end{array}$} \\
\hline & A & $\mathrm{B}$ & $\mathrm{C}$ & $\mathrm{D}$ & $R_{M 0}$ & $b$ & $\mathrm{R}^{2}$ & $\mathrm{~F}$ & SD & \\
\hline 1 & -0.698 & -0.423 & -0.309 & -0.128 & 2.803 & -0.036 & 0.972 & 69.19 & 0.049 & 5.97 \\
\hline 2 & -0.562 & -0.465 & -0.408 & -0.34 & 0.822 & -0.014 & 0.987 & 153.61 & 0.013 & 1.96 \\
\hline 3 & -0.616 & -0.434 & -0.309 & -0.154 & 2.266 & -0.030 & 0.995 & 407.19 & 0.016 & 4.48 \\
\hline $4^{(b)}$ & -0.239 & 0 & 0.176 & 0.421 & 3.863 & -0.043 & 0.996 & 528.10 & 0.021 & 7.70 \\
\hline 5 & -0.483 & -0.265 & -0.128 & 0.043 & 2.793 & -0.034 & 0.992 & 242.37 & 0.024 & 4.84 \\
\hline 8 & -0.635 & -0.503 & -0.382 & -0.196 & 2.087 & -0.029 & 0.990 & 203.17 & 0.022 & 4.38 \\
\hline 9 & -0.602 & -0.527 & -0.479 & -0.423 & 0.516 & -0.012 & 0.991 & 225.89 & 0.009 & 1.85 \\
\hline $11^{(b)}$ & 0.239 & 0.524 & 0.736 & 1.010 & 5.046 & -0.051 & 0.997 & 677.18 & 0.021 & 7.91 \\
\hline $13^{(b)}$ & 0.383 & 0.673 & 0.857 & 1.085 & 4.757 & -0.046 & 0.992 & 251.39 & 0.032 & 8.43 \\
\hline 14 & -0.717 & -0.562 & -0.454 & -0.36 & 1.541 & -0.024 & 0.986 & 141.16 & 0.022 & 2.18 \\
\hline DPPH-H & -0.434 & -0.252 & -0.106 & 0.042 & 2.567 & -0.031 & 0.997 & 685.90 & 0.013 & 4.70 \\
\hline
\end{tabular}
9, 11, 13, 14 and DPPH-H ${ }^{\text {a }}$

${ }^{a}$ Four determinations on silica gel RP- $18 \mathrm{~F}_{254 \mathrm{~S}}$ (Merck), with ethanol concentrations in ethanolwater mixture: $\mathrm{A}=95 \%, \mathrm{~B}=90 \%, \mathrm{C}=85 \%$ and $\mathrm{D}=80 \%$; ${ }^{(\mathrm{b})}$ For major spot (from oxidized or reduced forms). 
One can see from Table 6 that the most hydrophobic compounds are $\mathbf{1 1}$ and 13, and the least hydrophobic are the starting chlorinated materials. The molecular hydrophobicity decreases in the following order: $R_{M 0} 11>R_{M 0} 13>R_{M 0} 4>R_{M 0} 1>R_{M 0} 5>R_{M 0} \mathrm{DPPH}-\mathrm{H}>R_{M 0} 3>R_{M 0} 8>$ $R_{M 0} 14>R_{M O} 2>R_{M 0}$ 9. A plot of the experimental $R_{M 0}$ values versus the calculated $A \log P$ partition coefficient ${ }^{19,20}$ (Figure 9) presents a satisfactory linear correlation, as indicated in Table 7 and in equation 3.

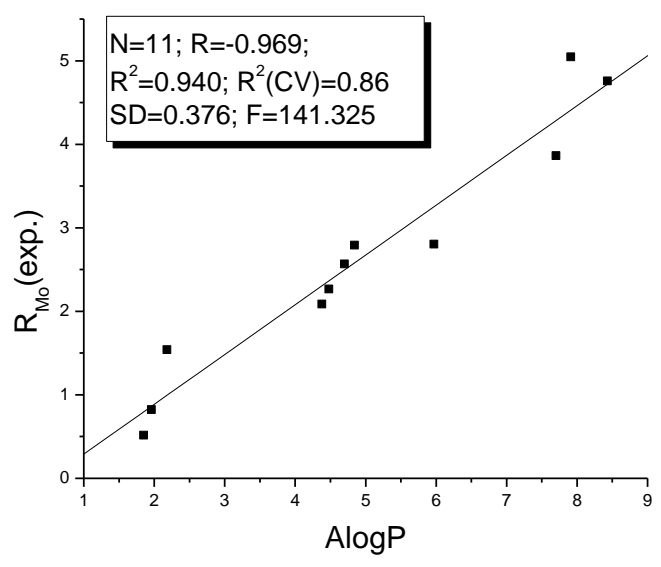

Figure 9. $R_{M o}$ vs $A \log P$ for compounds 1, 2, 3, 4, 5, 8, 9, 11, 13, 14 and DPPH-H.

$$
R_{M 0}(\text { calcd. })=0.596( \pm 0.050) A \log P-0.306
$$

Table 7. Comparison between $R_{M 0}$ (exp.) and $R_{M 0}$ (calcd. from $A \log P$ by equation 3 )

\begin{tabular}{|c|c|c|c|c|}
\hline \multirow{2}{*}{ Compound } & \multirow{2}{*}{$A \log P$} & \multicolumn{3}{|c|}{$R_{M 0}$} \\
\hline & & Exp. & Calcd. & Residual \\
\hline 1 & 5.97 & 2.803 & 3.252 & 0.449 \\
\hline 2 & 1.96 & 0.822 & 0.862 & 0.040 \\
\hline 3 & 4.48 & 2.266 & 2.364 & 0.098 \\
\hline $4^{a}$ & 7.70 & 3.863 & 4.283 & 0.420 \\
\hline 5 & 4.84 & 2.793 & 2.578 & 0.215 \\
\hline 8 & 4.38 & 2.087 & 2.304 & 0.217 \\
\hline 9 & 1.85 & 0.516 & 0.796 & 0.280 \\
\hline $11^{\mathrm{a}}$ & 7.91 & 5.046 & 4.408 & 0.638 \\
\hline $13^{a}$ & 8.43 & 4.757 & 4.718 & 0.039 \\
\hline 14 & 2.18 & 1.541 & 0.993 & 0.548 \\
\hline DPPH-H & 4.70 & 2.567 & 2.495 & 0.072 \\
\hline
\end{tabular}

${ }^{\mathrm{a}}$ For major spot (from oxidized or reduced forms) 


\section{Conclusions}

The reaction between 1,1-diphenylhydrazine (1) and NBD-Cl (2) in the presence of $\mathrm{NaHCO}_{3}$ proceeds normally by an $S_{N} A r$ mechanism affording 1-(4-nitrobenzofurazan-7-yl)-2,2diphenylhydrazine (3), but then this compound reacts further with $\mathbf{1}$ by ipso-substitution of its nitro group yielding 4,7-benzofurazandione-(bis-1,1-diphenylhydrazone) (4), whose structure was proven by IR and NMR spectra, $N$-methylation to $\mathbf{5}$, and by X-ray diffraction of single crystals. A dinitro congener of $\mathbf{3}$, namely 1-(5,7-dinitrobenzofurazan-4-yl)-2,2diphenylhydrazine (8) resulted both by homolytic nitration of $\mathbf{3}$ with gaseous $\mathrm{NO}_{2}$, and by heterolytic $\mathrm{S}_{\mathrm{N}} \mathrm{Ar}$ attack of $\mathbf{1}$ on chloro-dinitro-benzoxadiazole (DNBD-Cl, 9). Like the trinitro compound DPPH-H, the dinitro derivative $\mathbf{8}$ does not react with $\mathbf{1}$, whereas the mono-nitro congener $\mathbf{3}$ does. These three 2,2-diphenyl-1-EWG-hydrazines, namely 2,2-diphenyl-1picrylhydrazine (DPPH-H), $\mathbf{3}$, and $\mathbf{8}$, form persistent hydrazyls on oxidation, but unlike DPPH which does not dimerize in solution, $\mathbf{3}$ and $\mathbf{8}$ do. The unstable dimers $\mathbf{3}$ and $\mathbf{8}$ evolve $2 \mathrm{NO}_{2} \rightleftharpoons$ $\mathrm{N}_{2} \mathrm{O}_{4}$ and yield stable blue compounds $\mathbf{1 1}$ and 13, respectively. The structure of $\mathbf{1 3}$ was firmly established by X-ray diffraction of single crystals using synchrotron radiation.

Redox processes of $\mathbf{3}, \mathbf{4}$ and $\mathbf{8}$ were investigated chemically and by cyclic voltammetry. Like DPPH-H, the two congeners $\mathbf{3}$ and $\mathbf{8}$ react reversibly with bases such as tertiary amines forming stable anions. Compounds $\mathbf{3}$ and $\mathbf{8}$ absorb visible light at longer wavelengths than DPPH-H, and the quinone-diiminic structures 4, 11 and 13 exhibit even stronger bathochromic effects. On oxidation with $\mathrm{KMnO}_{4}$, compounds 4,11 and 13 yield persistent free radicals, presumably radical-cations.

\section{Acknowledgements}

This research was carried out within the research programme "Coordinative and Supramolecular Chemistry" of the Institute of Physical Chemistry, financed by the Roumanian Academy. We thank Dr. Gernot Buth for the continuous support and development of the Small Crystal Diffractometry Beamline at the ANKA Synchrotron in Karlsruhe.

\section{Experimental Section}

General. Commercial chemicals were purchased: from Merck, $N, N$-diphenylhydrazinium chloride (1-HCl), 15-crown-5, methyl iodide, TLC glass plates with silica gel $60 \mathrm{~F}_{254}$ (for analytical TLC), silica gel 60 PLC-F $_{254}$ (for preparative TLC), silica gel RP-18 $\mathrm{F}_{254 \mathrm{~S}}$ (for RPTLC) and silica gel $60(0.063-0.200 \mathrm{~mm})$ for column chromatography (1.07734 code); from Fluka, DPPH-H, tetra- $n$-butylammonium perchlorate and ammonium sulfamate; and from Aldrich, 4-chloro-7-nitrobenzofurazan (2); from the Institute of Stable Isotopes Cluj Romania, 
$\mathrm{Na}^{15} \mathrm{NO}_{2}$ (98.3\% enriched). Compound $9{ }^{15}$ and picryl chloride $14{ }^{24}$ were prepared according to literature data.

Electronic absorption spectra were recorded with a Unicam-UV-VIS spectrophotometer using Vision Software V.3.33. NMR spectra were recorded with a Varian Gemini 300 BB spectrometer (300 MHz for ${ }^{1} \mathrm{H}-\mathrm{NMR}$ and $75 \mathrm{MHz}$ for ${ }^{13} \mathrm{C}-\mathrm{NMR}$ ) using TMS as internal standard. Fouriertransform IR spectra were recorded on a Bruker Vertex 70 spectrometer with horizontal device for attenuated reflectance and diamond crystal, on a spectral window ranging from 4000 to 400 $\mathrm{cm}^{-1}$. EPR spectra were recorded with a Jeol JES-FA 100 instrument. Mass spectra were recorded with Varian 1200 L/MS/MS Triple Quadrupole with ESI interface both positive and negative ionization, fragmentation by collision with argon at $1.5 \mathrm{mTorr}$. Melting points have been recorded in open capillary with Electrothermal IA 9000 Series of digital melting point instruments. Cyclic voltammetric measurements were performed with a conventional threeelectrode glass cell by means of a PAR-273-A potentiostat, and all solutions were prepared by using acetonitrile. As reference electrode, a $\mathrm{Ag} / \mathrm{AgCl}$ electrode immersed in a $0.1 \mathrm{M}$ supporting electrolyte solution was used, linked to the main compartment of the cell by means of a Vycor plug. A platinum disk (surface area, $0.07 \mathrm{~cm}^{2}$ ) and a platinum wire were used as the working and counter electrode, respectively. As supporting electrolyte, tetra- $n$-butylammonium perchlorate (TBAP) was used at a concentration of $0.1 \mathrm{M}$.

It should be stressed that the atom numberings indicated below are only for assistance with NMR assignments.

1-(4-Nitrobenzofurazan-7-yl)-2,2-diphenyl-hydrazine (3) and 4,7-benzofurazan-dione-(bis1,1-diphenylhydrazone) or $\mathbf{6 , 6}$ '-dinitrobibenzofurazan-4,4'-ylidene-7,7'-dione bis-(2,2diphenylhydrazone) (4). General procedure starting from (1) and (2)

1,1-Diphenylhydrazine 1 and sodium hydrogen carbonate (molar ratio $1: 2.5$ ) were stirred for 15 min. at room temperature in ethanol $(50 \mathrm{~mL} / 1 \mathrm{~g}$ of $\mathbf{1})$, then NBD-Cl (2) was added (equimolar ratio $1: 2$ ) and the mixture was refluxed for one hour. The brown-violet solution was diluted with water till a precipitate was formed; the mixture was acidified with $1 \mathrm{~N}$ hydrochloric acid to $\mathrm{pH}=1$; liquid-liquid extraction with methylene chloride followed till the organic extract was colorless. The separated and dried organic solvent was evaporated under reduced pressure, and the residue was dried in a desiccator over $\mathrm{CaCl}_{2}$. The products were separated and purified by preparative TLC (silica gel 60 PLC-F $_{254}$, with dichloromethane : toluene $=1: 1 \mathrm{v} / \mathrm{v}, \mathrm{R}_{\mathrm{f}} \mathbf{3}=0.25$, yield $30 \%$ and $R_{\mathrm{f}} \mathbf{4}=0.575$, yield $21 \%$ ).

Atom numberings in the following formulas are ad hoc assistance for NMR assignments and do not follow IUPAC rules. 


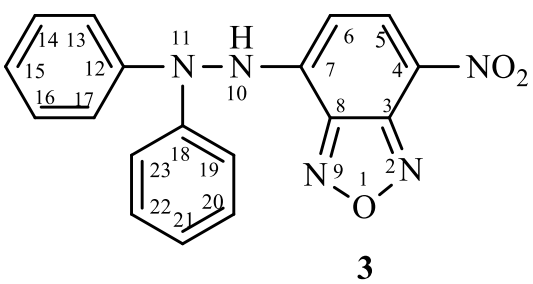

1-(4-Nitrobenzofurazan-7-yl)-2,2-diphenyl-hydrazine (3). Brick-red crystals, m.p. 148-149 ${ }^{\circ} \mathrm{C}$. ESI-MS, $(m / z)$; for $\mathrm{C}_{18} \mathrm{H}_{13} \mathrm{~N}_{5} \mathrm{O}_{3}(3, \mathrm{M}=347)$, in negative and positive: $[\mathrm{M}-\mathrm{H}]^{-} 346$ and $[\mathrm{M}+\mathrm{H}]^{+}$ 348. FT-IR (solid ATR, $v \mathrm{~cm}^{-1}$ ): 994m, 1272s, 1307vs, 1367m, 1441s, 1492s, 1556w, 1586m, 1752w, 2852m, 2922s, 3295s. ${ }^{1} \mathrm{H}-\mathrm{NMR}\left(\mathrm{CDCl}_{3}, \delta \mathrm{ppm}, J \mathrm{~Hz}\right): 8.46(\mathrm{~d}, 1 \mathrm{H}, \mathrm{H}-5,8.6), 8.06(\mathrm{bs}$, $1 \mathrm{H}, \mathrm{NH}$, deuterable), 7.35(dd, 4H, H-14, H-16 and H-20, H-22, 8.4, 7.4), 7.20(dd, 4H, H-13, H17 and $\mathrm{H}-19, \mathrm{H}-23,1.3,8.4), 7.15(\mathrm{tt}, 2 \mathrm{H}, \mathrm{H}-15$ and $\mathrm{H}-21,1.3,7.4), 6.78(\mathrm{~d}, 1 \mathrm{H}, \mathrm{H}-6,8.6) .{ }^{13} \mathrm{C}-$ NMR $\left(\mathrm{CDCl}_{3}, \delta \mathrm{ppm}\right): 144.97(\mathrm{C}-12$ and $\mathrm{C}-18), 143.93(\mathrm{Cq}-1), 142.70(\mathrm{C}-3), 142.25(\mathrm{Cq})$, 135.77(C-5), 130.07(Cq), 129.82(C-14, C-16 and C-20, C-22), 124.71(C-15 and C-21), 119.70(C-13, C-17 and C-19, C-23), 110.87(C-6). $\mathrm{C}_{18} \mathrm{H}_{13} \mathrm{~N}_{5} \mathrm{O}_{3}$ (347.31): calcd. C 62.25, $\mathrm{H} 3.77$, N 20.16; found C 62.23, H 3.75, N 20.13\%.

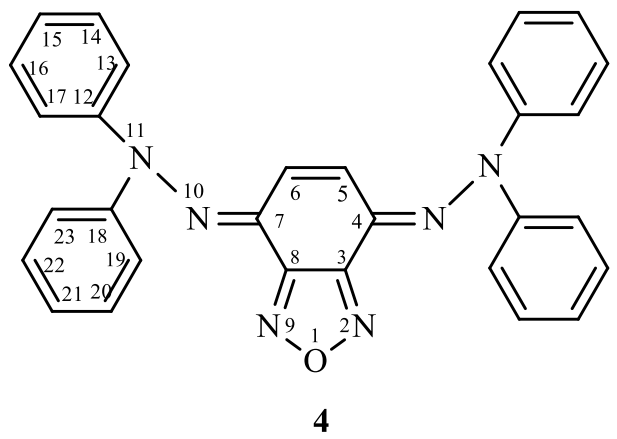

4,7-Benzofurazandione-(bis-1,1-diphenylhydrazone) (4). Deep-red crystals with metallic luster, mixture containing small amounts of reduced form (no precise m.p. or elemental analysis). ESI-MS, $m / z$; for mixture $\mathrm{C}_{30} \mathrm{H}_{22} \mathrm{~N}_{6} \mathrm{O}(\mathbf{4}, \mathrm{M}=482)$ and $\mathrm{C}_{30} \mathrm{H}_{24} \mathrm{~N}_{6} \mathrm{O}(\mathbf{1 4}, \mathrm{M}=484)$, in positive: $[\mathrm{M}]^{+\bullet} 482,[\mathrm{M}+\mathrm{H}]^{+} 483,[\mathrm{M}]^{+\bullet} 484,[\mathrm{M}+\mathrm{H}]^{+} 485$. FT-IR (ATR in solid, $v \mathrm{~cm}^{-1}$ ): $3059 \mathrm{w}$, $2921 \mathrm{w}, 2852 \mathrm{w}, 1586 \mathrm{~m}, 1521 \mathrm{~s}, 1480 \mathrm{vs}, 1396 \mathrm{~m}, 1330 \mathrm{~m}, 1203 \mathrm{vs}, 1130 \mathrm{~m}, 1078 \mathrm{w}, 1037 \mathrm{~s}, 993 \mathrm{~m}$, 946m, 871w, 788w, 740m, 691m, 607w, 582w, 542w. ${ }^{1} \mathrm{H}-\mathrm{NMR}\left(\mathrm{CDCl}_{3}, \delta \mathrm{ppm}, J \mathrm{~Hz}\right): 7.36(\mathrm{dd}$, $8 \mathrm{H}, \mathrm{H}-14, \mathrm{H}-16$ and $\mathrm{H}-20, \mathrm{H}-22,8.2,7.4), 7.26(\mathrm{tt}, 4 \mathrm{H}, \mathrm{H}-15$ and $\mathrm{H}-21,1.4,7.4), 7.20(\mathrm{dd}, 8 \mathrm{H}, \mathrm{H}-$ 13, $\mathrm{H}-17$ and H-19, H-23, 1.4, 8.2), 5.42(s, 2H, H-5, H-6). ${ }^{13} \mathrm{C}-\mathrm{NMR}\left(\mathrm{CDCl}_{3}, \delta \mathrm{ppm}\right): 150.11(\mathrm{C}-$ 4, C-7), 146.28(C-12, C-18), 129.77(C-14, C-16 and C-20, C-22), 128.91(Cq), 125.88(C-15 and C-21), 122.51(C-13, C-17 and C-19, C-23), 119.24(C-5, C-6). Note that the atom numbering for the NMR assignments differs from the one in the deposited CIF file CCDC-812719.

\section{4,7-Benzofurazandione-(bis-1,1-diphenylhydrazone) (4). General procedure starting from compounds (1) and (3)}

1,1-Diphenylhydrazine (1) and sodium hydrogen carbonate (molar ratio $1: 2$ ) were stirred for 15 min. at room temperature in ethanol $(50 \mathrm{~mL} / \mathrm{g}$ of $\mathbf{1})$, then compound 3 was added (equimolar 
ratio) and the mixture was refluxed for one hour. The red-violet reaction mixture was worked up as described above. The red product 4 was obtained in $18 \%$ yield.

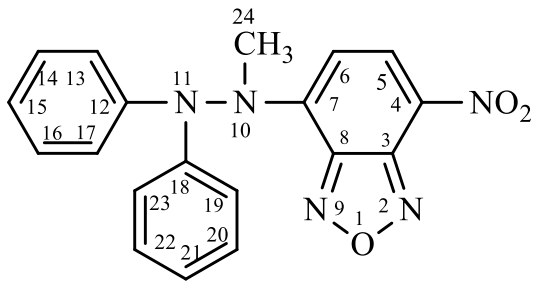

5

1-Methyl-1-(4-nitrobenzofurazan-7-yl)-2,2-diphenylhydrazine (5). Under phase-transfer catalytic conditions by stirring in methylene chloride with compound $\mathbf{3}$, solid powdered $\mathrm{NaOH}$, 15-crown-5 and $\mathrm{CH}_{3} \mathrm{I}$ in molar ratios $3: \mathrm{NaOH}: 15-\mathrm{Crown}-5: \mathrm{CH}_{3} \mathrm{I}=1: 1: 1.5: 6$ as follows: For $20 \mathrm{~mL} / 0.5 \mathrm{~g}$ reactant mixture, the freshly ground $\mathrm{NaOH}$ was suspended in $\mathrm{CH}_{2} \mathrm{Cl}_{2}$ then 15 crown-5 was added and the mixture was stirred till complete dissolution occurred. Then $\mathbf{3}$ and $\mathrm{CH}_{3} \mathrm{I}$ were added and the mixture was stirred at room temperature for $5 \mathrm{hrs}$, when the red color turned yellow-orange. After removal of the solvent under vacuum, the product 5 was isolated and purified by preparative TLC (Silica Gel $60 \mathrm{PLC} \mathrm{F}_{254}$, methylene chloride : toluene $=1: 1 \mathrm{v} / \mathrm{v}, \mathrm{R}_{\mathrm{f}}$ $5=0.375$ ). Yield $52 \%$ in yellow-orange crystals, m.p. $164.5-165^{\circ} \mathrm{C}:$ ESI-MS, $\mathrm{m} / z$; for $\mathrm{C}_{19} \mathrm{H}_{15} \mathrm{~N}_{5} \mathrm{O}_{3}\left(5, \mathrm{M}=361\right.$ ), in positive: $[\mathrm{M}+\mathrm{H}]^{+} 362$. FT-IR (ATR in solid, $v \mathrm{~cm}^{-1}$ ): $3234 \mathrm{w}, 3044 \mathrm{w}$, $2926 \mathrm{w}, 2855 \mathrm{w} ; 1620 \mathrm{~m} ; 1587 \mathrm{~m} ; 1546 \mathrm{vs} ; 1491 \mathrm{vs} ; 1460 \mathrm{~m} ; 1448 \mathrm{~m} ; 1422 \mathrm{~m} ; 1369 \mathrm{w} ; 1311 \mathrm{vs}$; $1291 \mathrm{vs}, 1270 \mathrm{vs}, 1204 \mathrm{~m}, 1175 \mathrm{~m}, 1133 \mathrm{w}, 1107 \mathrm{w}, 1082 \mathrm{~m}, 1042 \mathrm{w}, 1031 \mathrm{w}, 1003 \mathrm{~m}, 977 \mathrm{w}, 914 \mathrm{~m}$, 866w, 825w, 779w, 750s, 739m, 693m, 630w, 616w. ${ }^{1} \mathrm{H}-\mathrm{NMR}\left(\mathrm{CDCl}_{3}, \delta \mathrm{ppm}, J \mathrm{~Hz}\right): 8.41(\mathrm{~d}$, 1H, H-5, 9.0), 7.34(dd, 4H, H-14, H-16 and H-20, H-22, 8.4, 7.4), 7.14(dd, 4H, H-13, H-17 and $\mathrm{H}-19, \mathrm{H}-23,1.3,8.4)$; 7.11(tt, 2H, H-15 and H-21, 1.3, 7.4); 6.75 (bs, 1H, H-6), 4.01(bs, 3H, H24), broadened signals for H-6 and C-6 due to hindered rotation caused by the methyl group. ${ }^{13} \mathrm{C}-\mathrm{NMR}\left(\mathrm{CDCl}_{3}, \delta \mathrm{ppm}\right): 145.44(\mathrm{Cq}), 144.77(\mathrm{C}-12$ and $\mathrm{C}-18), 143.87(\mathrm{C}-1), 142.26(\mathrm{C}-3)$, 135.05(C-5), 129.88(C-14, C-16 and C-20, C-22), 129.66(Cq), 124.34(C-15 and C-21), 119.21(C-13, C-17 and C-19, C-23), 102.93(bs, C-6); 40.72(C-24). $\mathrm{C}_{19} \mathrm{H}_{15} \mathrm{~N}_{5} \mathrm{O}_{3}$ (361.34): calcd. C 63.15, H 4.18, N 19.38; found C 63.13, H 4.16, N 19.35\%.

7,7'-Bis-benzofurazanylidene-4,4'-bis-(2,2-diphenylhydrazone) benzofurazan-7-yl)-2,2-diphenylhydrazine

(8), benzofurazanylidene-4,4'-bis-(2,2-diphenylhydrazone) oxidation of (3)

An excess of finely ground potassium permanganate was added to a solution of $\mathbf{3}$ in $\mathrm{CH}_{2} \mathrm{Cl}_{2}(0.5$ $\mathrm{g} \mathrm{KMnO}_{4} / 1 \mathrm{~g}$ of 3). After stirring for $24 \mathrm{hrs}$ at room temperature the mixture was centrifuged, retaining the supernatant solution and the solid was extracted three times with $\mathrm{CH}_{2} \mathrm{Cl}_{2}$. The combined solutions were concentrated in vacuum, and the three products were separated by preparative TLC (Silica Gel 60 PLC-F 254 , eluent methylene chloride : toluene = 1:1 v/v): a redviolet zone for $\mathbf{8}\left(\mathrm{R}_{\mathrm{f}}=0.475\right.$, yield $\left.5 \%\right)$, a blue zone for $11\left(\mathrm{R}_{\mathrm{f}}=0.706\right.$, yield $\left.14 \%\right)$, and a blue zone for $13\left(R_{\mathrm{f}}=0.800\right.$, yield $\left.11 \%\right)$. 


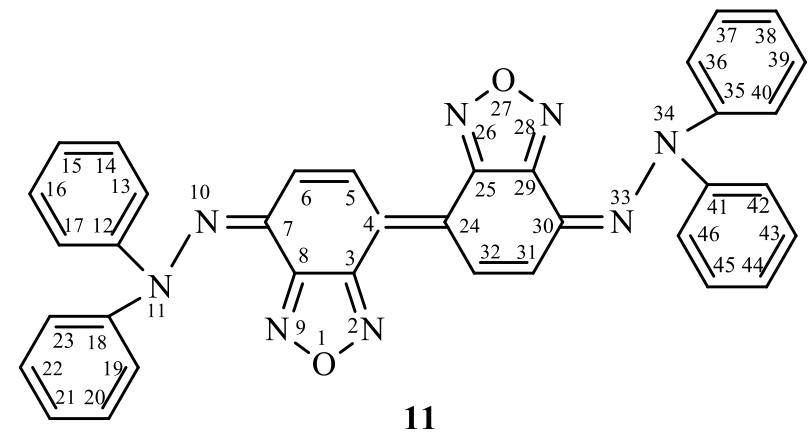

7,7'-Bis-benzofurazanylidene-4,4'-bis-(2,2-diphenylhydrazone) (11) Deep blue solid with metallic luster, mixture containing small amounts of reduced form (no precise m.p. or elemental analysis). ESI-MS, $m / z$; for mixture $\mathrm{C}_{36} \mathrm{H}_{24} \mathrm{~N}_{8} \mathrm{O}_{2}(\mathbf{1 1}, \mathrm{M}=600)$ and $\mathrm{C}_{36} \mathrm{H}_{26} \mathrm{~N}_{8} \mathrm{O}_{2}(\mathbf{1 8}, \mathrm{M}=602)$, in positive: $[\mathrm{M}]^{+\bullet} 600,[\mathrm{M}+\mathrm{H}]^{+} 601,[\mathrm{M}]^{+\bullet}$ 602. FT-IR(ATR in solid, $v \mathrm{~cm}^{-1}$ ): 2924vs, 2854s, $1734 \mathrm{w}, 1590 \mathrm{w}, 1480 \mathrm{~s}, 1449 \mathrm{~s}, 1413 \mathrm{w}, 1370 \mathrm{~m}, 1313 \mathrm{~m}, 1276 \mathrm{~m}, 1219 \mathrm{~m}, 1184 \mathrm{~m}, 1085 \mathrm{w}, 1056 \mathrm{w}$, 999w, 971w, 888w, 749m, 693m, 580w. ${ }^{1} \mathrm{H}-\mathrm{NMR}\left(\mathrm{CDCl}_{3}, \delta \mathrm{ppm}, J \mathrm{~Hz}\right): 8.87(\mathrm{~s}, 1 \mathrm{H}, \mathrm{NH})$, 8.66(s, 1H, NH), 8.20(d, 2H, H-5, H-32, 9.3), 7.30 (d, 2H, H-6, H-31, 9.3), 7.48 7.15 (m, 20H, H-arom). Doublet peaks at 8.10 (H-5) and $5.86 \mathrm{ppm}(\mathrm{H}-6)$ with $J=10.5 \mathrm{~Hz}$ confirms presence of a reduced form in a tenfold lower amount. ${ }^{13} \mathrm{C}-\mathrm{NMR}\left(\mathrm{CDCl}_{3}, \delta \mathrm{ppm}\right): 151.58(\mathrm{Cq}), 148.02(\mathrm{Cq})$, 144.49(Cq), 141.43(Cq), 129.39(C-14, C-16 and C-20, C-22), 124.96(C-13, C-17 and C-19, C23 or C-36, C-40 and C-42, C-46), 123.78(C-13, C-17 and C-19, C-23 or C-36, C-40 and C-42, C-46), 122.66(C-15, C-21, C-38, C-44), 119.80(C-5, C-32 or C-6, C-31), 119.62(C-5, C-32 or C6, C-31).

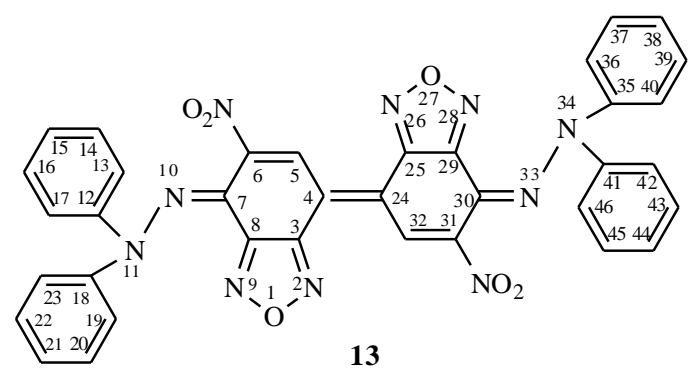

7,7'-Bis-5,5'-dinitro-benzofurazanylidene-4,4'-bis-(2,2-diphenylhydrazone) (13). Deep blue solid with metallic luster, mixture containing small amounts of reduced form (no precise m.p. or elemental analysis). ESI-MS, $\mathrm{m} / z$; for mixture $\mathrm{C}_{36} \mathrm{H}_{22} \mathrm{~N}_{10} \mathrm{O}_{6}(\mathbf{1 3}, \mathrm{M}=690)$ and $\mathrm{C}_{36} \mathrm{H}_{24} \mathrm{~N}_{10} \mathrm{O}_{6}(\mathbf{1 9}$, $\mathrm{M}=692$ ), in positive: $[\mathrm{M}]^{+\bullet} 690,[\mathrm{M}+\mathrm{H}]^{+} 691,\left[\mathrm{M}^{+\bullet} 692,[\mathrm{M}+\mathrm{H}]^{+}\right.$693. FT-IR (solid ATR), $\mathrm{cm}^{-1}$ : 963m, 1204vs, 1305m, 1366m, 1451m, 1480vs, 1589s, 1725w, 2856m, 2923s. ${ }^{1} \mathrm{H}-\mathrm{NMR}\left(\mathrm{CDCl}_{3}\right.$, $\delta$ ppm, $J$ Hz): 8.70(s, 2H, H-5), 7.37(dd, 4H, H-14, H-16 and H-20, H-22, 8.4, 7.2), 7.31(tt, 2H, $\mathrm{H}-15$ and $\mathrm{H}-21,1.5,7.2), 7.23(\mathrm{dd}, 4 \mathrm{H}, \mathrm{H}-13, \mathrm{H}-17$ and $\mathrm{H}-19, \mathrm{H}-23,1.5,8.4) .{ }^{13} \mathrm{C}-\mathrm{NMR}\left(\mathrm{CDCl}_{3}\right.$, $\delta$ ppm): 144.68(C-12, C-18), 129.31(C-14, C-16 and C-20, C-22), 127.68(C-15 and C-21), 123.66(C-13, C-17 and C-19, C-23), 120.57(C-5), 120.35(Cq), 152.26(C-4, C-7), 147.96(Cq), 142.03(Cq-3), 129.35(Cq). Note that the atom numbering for the NMR assignments differs from the one in the deposited CIF file CCDC-812720. 


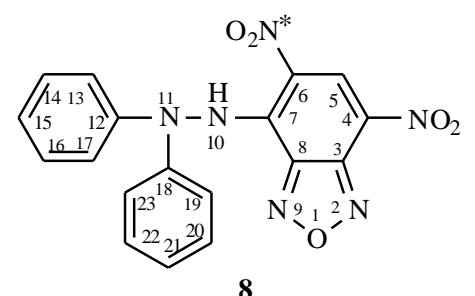

1-(4,6-Dinitro-benzofurazan-7-yl)-2,2-diphenylhydrazine (8). Violet crystals, m.p. 184-186 ${ }^{\circ} \mathrm{C}$. ESI-MS, $m / z$; for $\mathrm{C}_{18} \mathrm{H}_{12} \mathrm{~N}_{6} \mathrm{O}_{5}\left(\mathbf{8}, \mathrm{M}=392\right.$ ), in negative: [M-H] ${ }^{-} 391$. FT-IR(ATR in solid, $v \mathrm{~cm}^{-1}$ ): 3226m, 3066w, 2907w, 1625s, 1573s, 1525s, 1485s, 1415m, 1378m, 1299vs, 1269vs, 1180s, 1125s, 1072m, 1027m, 1000m, 938m, 892w, 854w, 814w, 776w, 738m, 687m, 650m, 577w. ${ }^{1} \mathrm{H}-\mathrm{NMR}\left(\mathrm{CDCl}_{3}, \delta \mathrm{ppm}, J \mathrm{~Hz}\right): 11.73(\mathrm{~s}, 1 \mathrm{H}, \mathrm{H}-\mathrm{N}$, deuterable), 9.36(s, 1H, H-5), 7.36(dd, 4H, H-meta, H-14, H-17 and H-20, H-22, 7.5, 8.4), 7.21(dd, 4H, H-ortho, H-13, H-17 and $\mathrm{H}-19, \mathrm{H}-23,1.3,8.4), 7.18(\mathrm{tt}, 2 \mathrm{H}, \mathrm{H}-$ para, $\mathrm{H}-15$ and $\mathrm{H}-21,1.3,7.5) .{ }^{13} \mathrm{C}-\mathrm{NMR}\left(\mathrm{CDCl}_{3}, \delta\right.$ ppm): 144.68(C-12 and C-18), 143.97(C-1), 143.68(C-3), 137.13(C-4), 129.86(C-14, C-16 and C-20, C-22), 129.77(C-8), 129.69(C-5), 125.52(C-15 and C-21), 123.29(d, C-6), 120.35(C-13, C-17 and C-19, C-23). $\mathrm{C}_{18} \mathrm{H}_{12} \mathrm{~N}_{6} \mathrm{O}_{5}$ (392.31): calcd. C 55.10, H 3.08, N 21.42; found C 55.08, H $3.05, \mathrm{~N} 21.39 \%$.

1-(4,6-Dinitro-benzofurazan-7-yl)-2,2-diphenylhydrazine and its ${ }^{15} \mathrm{NO}_{2}$-labeled congener (8). General procedure starting from 3 by homolytic nitration. A solution of $30 \mathrm{mg} \mathrm{NaNO}_{2}$ or $\left[{ }^{15} \mathrm{~N}\right] \mathrm{NaNO}_{2}$ in $25 \mathrm{~mL} \mathrm{CH} \mathrm{Cl}_{2}$ was obtained with the help of 15-crown-5 (molar ratio $\mathrm{NaNO}_{2}$ : crown ether $=1: 1.5)$. Compound 3 was added to this solution (molar ratio $\left.3: \mathrm{NaNO}_{2}=1: 1.5\right)$ together with solid silica gel for column chromatography (ratio $0.5 \mathrm{~g}$ silicagel / $0.1 \mathrm{~g}$ of $\mathbf{3}$ ). The mixture was stirred for $24 \mathrm{hrs}$, monitoring the course of the reaction by TLC analysis (Silica Gel $60 \mathrm{~F}_{254}$, methylene chloride : toluene $\left.=1: 1 \mathrm{v} / \mathrm{v}\right)$ by following the decrease of $\mathbf{3}\left(\mathrm{R}_{\mathrm{f}}=0.25\right)$ and the formation of compound $\mathbf{8}\left(\mathrm{R}_{\mathrm{f}}=0.475\right)$. The mixture was centrifuged, retaining the supernatant solution, and the solid was extracted three times with $\mathrm{CH}_{2} \mathrm{Cl}_{2}$. The combined solutions were extracted twice with water with ammonium sulfamate, once with dilute hydrochloric acid with ammonium sulfamate, and finally again with water. The organic layer was dried over $\mathrm{Na}_{2} \mathrm{SO}_{4}$, the solvent was removed in vacuum, and the violet product was purified by preparative TLC (Silica Gel 60 PLC-F $254, \mathrm{CH}_{2} \mathrm{Cl}_{2}$ : toluene $=1: 1 \mathrm{v} / \mathrm{v}$ ), yield $40 \%$.

1-(4- $\left[{ }^{14} \mathrm{~N}\right]$ Nitro-6- $\left[{ }^{15} \mathrm{~N}\right]$ nitro-benzofurazan-7-yl)- 2,2-diphenylhydrazine, 8- ${ }^{15} \mathrm{~N}$. ESI-MS, $m / z$; for $\mathrm{C}_{18} \mathrm{H}_{12}{ }^{*} \mathrm{~N}_{6} \mathrm{O}_{5}\left(\mathbf{8}{ }^{-15} \mathbf{N}, \mathrm{M}=393\right.$ ), in negative: [M-H] ${ }^{-}$392. FT-IR (ATR in solid, $v \mathrm{~cm}^{-1}$ ): $3225 \mathrm{~m}, 3065 \mathrm{w}, 2923 \mathrm{~m}, 2855 \mathrm{w}, 1625 \mathrm{~s}, 1570 \mathrm{~s}, 1523 \mathrm{~s}, 1487 \mathrm{~s}, 1460 \mathrm{~s}, 1415 \mathrm{~m}, 1373 \mathrm{~m}, 1295 \mathrm{vs}$, 1264vs, 1175s, 1124s, 1073m, 1000m, 936m, 891w, 814w, 776w, 743m, 686m, 649m, 577w, 547w. ${ }^{1} \mathrm{H}-\mathrm{NMR}\left(\mathrm{CDCl}_{3}, \delta \mathrm{ppm}, J \mathrm{~Hz}\right): 11.73(\mathrm{~s}, 1 \mathrm{H}, \mathrm{H}-\mathrm{N}$, deuterable $), 9.36\left(\mathrm{~d}, 1 \mathrm{H}, \mathrm{H}-5,{ }^{3} J\left(\mathrm{H}^{5}-\right.\right.$ $\left.\left.{ }^{15} \mathrm{~N}\right)=1.9 \mathrm{~Hz}\right), 7.36(\mathrm{dd}, 4 \mathrm{H}, \mathrm{H}-m e t a, \mathrm{H}-14, \mathrm{H}-17$ and $\mathrm{H}-20, \mathrm{H}-22,7.3,8.5), 7.21(\mathrm{dd}, 4 \mathrm{H}, \mathrm{H}-$ ortho, $\mathrm{H}-13, \mathrm{H}-17$ and $\mathrm{H}-19, \mathrm{H}-23,1.3,8.5)$, 7.18(tt, $2 \mathrm{H}, \mathrm{H}-$ para, $\mathrm{H}-15$ and $\mathrm{H}-21,1.3,7.3) .{ }^{13} \mathrm{C}-$ NMR $\left(\mathrm{CDCl}_{3}, \delta \mathrm{ppm}\right): 144.68(\mathrm{C}-12$ and $\mathrm{C}-18), 143.96\left(\mathrm{~d}, \mathrm{C}-1,{ }^{2} J\left(\mathrm{C}^{1}{ }_{-}^{15} \mathrm{~N}\right)=2.7 \mathrm{~Hz}\right), 143.67(\mathrm{C}-3)$, 137.13(C-4), 129.86(C-14, C-16 and C-20, C-22), 129.77(C-8), 129.69(d, C-5, ${ }^{2} J\left(\mathrm{C}^{5}-{ }^{15} \mathrm{~N}\right)=2.1$ 
$\mathrm{Hz}), 125.53\left(\mathrm{C}-15\right.$ and C-21), $123.29\left(\mathrm{~d}, \mathrm{C}-6, J\left(\mathrm{C}^{6}{ }_{-}^{15} \mathrm{~N}\right)=17.9 \mathrm{~Hz}\right), 120.34(\mathrm{C}-13, \mathrm{C}-17$ and C-19, C-23). Elemental analysis $\mathrm{C}_{18} \mathrm{H}_{12} \mathrm{~N}_{6} \mathrm{O}_{5}$ (393.31): calcd. C 54.96, H 3.07, N 21.62; found C 54.94, H 3.05, N 21.59\%.

\section{1-(5,7-Dinitro-benzofurazan-4-yl)-2,2-diphenylhydrazine (8). General procedure starting} from NBD-Cl (2)

Nitration of 4-chloro-7-nitrobenzofurazan 2 (NBD-Cl or 4-chloro-7-nitro-2,1,3-benzoxadiazole) was carried out according to literature data. ${ }^{15}$ The dinitro-derivative 9 was separated from unreacted 2 by preparative TLC in 6\% yield (Silica Gel $60 \mathrm{PLC}_{2} \mathrm{~F}_{254}, \mathrm{CH}_{2} \mathrm{Cl}_{2}$ : methanol = $9: 1$ $\mathrm{v} / \mathrm{v}, \mathrm{R}_{\mathrm{f}} \mathbf{2}=1.0, \quad \mathrm{R}_{\mathrm{f}} \mathbf{9}=0.34$ ); m.p. for 9 found $143.5-144.5{ }^{\circ} \mathrm{C}$ (lit. ${ }^{15} 143-144{ }^{\circ} \mathrm{C}$ ). For the synthesis of $\mathbf{8}$ from $\mathbf{9}$, the procedure followed the operations indicated for obtaining $\mathbf{3}$ from $\mathbf{2}$; TLC monitoring showed that the reaction was completed in 15 minutes. The yield was $60 \%$ based on 9.

\section{X-Ray analysis}

Crystals suitable for single crystal X-ray diffraction were selected in perfluoroalkyl-ether oil. Single-crystal X-ray diffraction data of $\mathbf{4}$ were collected with graphite-monochromatized MoK $\alpha$ radiation $(\lambda=0.71073 \AA$ ) on a STOE IPDS II (Imaging Plate Diffraction System). Single-crystal $X$-ray diffraction data of $\mathbf{1 3}$ were collected using synchrotron radiation $(\lambda=0.80 \AA)$ on a STOE IPDS II at the ANKA synchrotron source in Karlsruhe. Raw intensity data were collected and treated with the STOE X-Area software Version 1.27. Data were corrected for Lorentz and polarisation effects while the dataset of $\mathbf{1 3}$ was also corrected for the intensity decay of the beam. The structures were solved with the direct methods program SHELXS of the SHELXTL PC suite programs, ${ }^{25}$ and were refined with the use of the full-matrix least-squares program SHELXL. ${ }^{25}$ Molecular diagrams were prepared using Diamond. ${ }^{26}$ All C, O, and $\mathrm{N}$ atoms were refined with anisotropic displacement parameters. All $\mathrm{H}$ atoms could be localized in the difference Fourier map and were refined without restraints. Table 8 summarizes the main data collection and refinement parameters.

Cambridge Database documents CCDC-812719 (4) and CCDC-812720 (13) contain the supplementary crystallographic data for this paper. These data can be obtained free of charge at www.ccdc.cam.ac.uk/conts/retrieving.html (or from the Cambridge Crystallographic Data Centre, 12 Union Road, Cambridge CB2 1EZ, UK; fax: (internat.) +44-1223/336-033; E-mail: deposit@ccdc.cam.ac.uk). In the Supplementary Material one can find packing diagrams for 4 and 13. 
Table 8. Crystallographic data for $\mathrm{C}_{30} \mathrm{H}_{22} \mathrm{~N}_{6} \mathrm{O}$ (4) and $\mathrm{C}_{36} \mathrm{H}_{22} \mathrm{~N}_{10} \mathrm{O}_{6}(\mathbf{1 3})$

\begin{tabular}{|c|c|c|}
\hline & 4 & 13 \\
\hline$f w\left[\mathrm{~g} \mathrm{~mol}^{-1}\right]$ & 482.54 & 690.64 \\
\hline crystal system & monoclinic & triclinic \\
\hline space group & $C 2 c$ & $P \overline{1}$ \\
\hline Cell $\quad a[\AA]$ & $20.014(4)$ & $5.483(1)$ \\
\hline$b[\AA]$ & $9.5335(19)$ & $9.621(2)$ \\
\hline$c[\AA]$ & $12.576(3)$ & $15.613(3)$ \\
\hline$\alpha\left[^{\circ}\right]$ & & $106.46(3)$ \\
\hline$\beta\left[^{\circ}\right]$ & $99.53(3)$ & $94.813)$ \\
\hline$\gamma\left[^{\circ}\right]$ & & $91.88(3)$ \\
\hline$V\left[\AA^{3}\right]$ & $2366.4(8)$ & $785.7(3)$ \\
\hline$Z$ & 4 & 1 \\
\hline$T[\mathrm{~K}]$ & 180 & 150 \\
\hline$\lambda[\AA]$ & Mo-K $\alpha$ & 0.80000 \\
\hline$d_{c}\left[\mathrm{~g} \mathrm{~cm}^{-3}\right]$ & 1.354 & 1.460 \\
\hline$\mu(\lambda)\left[\mathrm{mm}^{-1}\right]$ & 0.086 & 0.129 \\
\hline$F[000]$ & 1008 & 356 \\
\hline $2 \theta_{\max }\left[^{\circ}\right]$ & 54 & 54 \\
\hline measured reflexions & 8774 & 7413 \\
\hline unique reflexions & 2475 & 2301 \\
\hline$R_{\text {int }}$ & 0.0750 & 0.0937 \\
\hline $\begin{array}{l}\text { reflexions with } I> \\
2 \sigma(I)\end{array}$ & 2234 & 1930 \\
\hline refined parameters & 212 & 279 \\
\hline$R 1(I>2 \sigma(I))^{\mathrm{a}}$ & 0.0425 & 0.0526 \\
\hline$w R 2$ (all data) ${ }^{\mathrm{b}}$ & 0.1361 & 0.1485 \\
\hline
\end{tabular}

\section{References}

1. Golschmidt, S.; Renn, K. Ber. 1922, 55, 628.

2. Forrester, A. R.; Hay, J. M.; Thomson, R. H. Organic Chemistry of Stable Free Radicals, 1968; Academic Press: London, p 137.

3. (a) Balaban, A. T. Rev. Roum. Chim. 1971, 16, 725-737. (b) Istratoiu, R.; Pascaru, I.; Balaban, A. T. Z. Naturforsch. 1973, $28 b, 543$. 
4. (a) Viehe, H. G.; Merenyi, R.; Stella, L.; Janousek, Z. Angew. Chem., Int. Ed. Engl. 1979, 18, 917. (b) Viehe, H. G.; Janousek, Z.; Merenyi, R.; Stella, L. Acc. Chem. Res. 1985, 18, 148. (c) Viehe, H. G.; Janousek, Z.; Merenyi, R. (Eds.), Substituent Effects in Radical Chemistry D. Reidel: Dordrecht, 1986.

5. Baldock, R. W.; Hudson, P.; Katritzky, A. R.; Soti, F. J. Chem. Soc., Perkin Trans. 1 1974, 1422.

6. Dewar, M. J. S. J. Am. Chem. Soc. 1952, 74, 3353.

7. (a) Linnett, J. W. J. Am. Chem. Soc. 1961, 83, 2643; (b) Linnett, J. W. The Electronic Structure of Molecules, Methuen: London, 1964.

8. Caproiu, M. T.; Elian, M.; Grecu, N.; Negoita, N.; Balaban, A. T. J. Chem. Soc., Perkin Trans. 2 1983, 591.

9. (a) Boulton, A. J.; Katritzky, A. R.; Hamid, A. M. J. Chem. Soc. (C) 1967, 2005. (b) Li, J. J. In: Name Reactions. A Collection of Detailed Reaction Mechanisms. Springer: Berlin, 2006, $\mathrm{p} 73$.

10. (a) Hallé, J.-C.; Mokhtari, M.; Soulié, P.; Pouet, M.-J. Can. J. Chem. 1997, 75, 1240. (b) Crampton, M. R.; Pearce, L. M.; Rabbitt, L. C. J. Chem. Soc., Perkin Trans. 2 2002, 257.

11. Terrier, F. Nucleophilic Aromatic Displacement, VCH: Weinheim, 1991, New York: Chem. Rev. 1982, 82, 77.

12. Covaci, I. C.; Constantinescu, T.; Caproiu, M. T.; Caldararu, H.; Ionita, P.; Balaban, A. T. Pol. J. Chem. 2001, 75, 1427.

13. (a) Ionita, P.; Constantinescu, T.; Caproiu, M. T.; Caldararu, H.; Balaban, A. T. J. Labelled Comp. Radiopharm. 1998, 41, 791. (b) Caproiu, M. T.; Covaci, I. C.; Ionita, P.; Luca, C.; Constantinescu, T.; Balaban, A. T. J. Radioanal. Nucl. Chem. 1999, 242, 773.

14. Kropp, P. J.; Breton, G. W.; Craig, S. L.; Crawford, S. D.; Durland, Jr., W. F.; Jones, III, J. E.; Raleigh, J. S. J. Org. Chem. 1995, 60, 4146.

15. Sharnin, G. P.; Levinson, F. S.; Akimova, S. A.; Hasanov, R. H. USSR Pat. 627129, 1978; Chem. Abstr. 1979, 90, P23063v.

16. Zilic, D.; Pajic, D.; Juric, M.; Molcanov, K.; Rakvin, B.; Planinic, P.; Zadro, K. J. Magn. Reson. 2010, 207, 34.

17. Adams, R.; Holmes, R. R. J. Am. Chem. Soc. 1952, 74, 3038.

18. Hansch, C.; Leo, A. Substituent Constants for Correlation Analysis in Chemistry and Biology, Wiley: New York, 1979.

19. Todeschini, R.; Consonni, V.; Pavan, M.; Mauri, A.; Ballabio, D. Dragon v. 5.5 (Talete srl, via V. Pisani, 13-20124, Milano, Italy) 2007, http://www.talete.mi.it.

20. Viswanadhan, V. N.; Ghose, A. K.; Revankar, G. R.; Robins, R. K. J. Chem. Inf. Comput. Sci. 1989, 29, 163.

21. Soczewinski, E. Anal. Chem. 1969, 41, 179.

22. Kossoy, A. D.; Risley, D. S.; Kleyle, R. M.; Nurok, D. Anal. Chem. 1992, 64, 1345. 
23. Radutiu, A. C.; Baciu, I.; Caproiu, M. T.; Draghici, C.; Beteringhe, A.; Ionita, G.; Ionita, P.; Spataru, T.; Spataru, N.; Baratoiu, R. D.; Constantinescu, T.; Balaban, A. T. ARKIVOC, 2009, (xiii), 342.

24. Ionita, P.; Caproiu, M. T.; Balaban, A. T. Rev. Roum. Chim. 2000, 45, 935.

25. Sheldrick, G. M. SHELXTL PC Version 5.1, Bruker Analytical X-ray Systems, Karlsruhe, 2000 .

26. Diamond Version 2.1d, K. Brandenburg, Crystal Impact GbR, 1996-2000. 